\title{
Pattern Generalization Processing of Elementary Students: Cognitive Factors Affecting the Development of Exact Mathematical Structures
}

\author{
F. D. Rivera ${ }^{1 *}$ \\ ${ }^{1}$ Department of Mathematics \& Statistics, San Jose State University, USA \\ Received 21 April 2018 - Revised 18 May 2018 - Accepted 22 May 2018
}

\begin{abstract}
The fundamental aim in this article is to elucidate cognitive factors that influence the development of mathematical structures and incipient generalizations in elementary school children on the basis of their work on patterns, including how they use various representational forms such as gestures, words, and arithmetical symbols to convey their expressions of generality. We describe approximate and exact pattern generalizations and three cognitive factors that mutually influence the emergence of mathematical structures, namely, competence with number relationships, competence with shape similarity, and competence with figural property construction, discernment, and justification. We also highlight various representational modes that elementary students use to capture their emergent structures and incipient generalizations, gradeappropriate use and understanding of variables via the notions of intuited and tacit variables, and ways in which their structural incipient generalizations support their early understanding of functions.
\end{abstract}

Keywords: pattern generalization, elementary students, abduction, induction, deductive closure, structural thinking in mathematics

\section{INTRODUCTION}

U.S. second grade student David (age 7 years) was asked to predict particular outcomes for each figural pattern shown in Figures 1 and 5 prior to any formal instruction on nonrepeating patterns. Looking at the incomplete pattern in Figure 1, he initially saw a house consisting of a triangle and two squares that increased according to stage number. In the case of the pattern shown in Figure 5, he saw squares that were enclosed by triangles (line 22). David's processing of the two tasks in the same clinical interview session exemplifies how an individual learner's assumptions, which we will call inferencing by abduction, tend to shape what he or she is able to generalize. Furthermore, and especially in this particular instance, several factors influenced David's ability to generalize. At the very least, the Figure 5 pattern seemed more complex to him than the Figure 1 pattern. "The main difference between complex and simple sets," Stavy and Babai (2008) point out, "is the amount of information [that] one has to process when comparing," which is further magnified in situations when "two stimuli are incongruent" (p. 175). Where David appeared to be consistent with his generalizing approach across the two tasks was the manner in which he perceived the stages in each pattern, that is, he saw them as whole objects that were similar. In Figure 1, for example, he saw a whole unit (stage 1) that increased by stage number (Figure 2), which then enabled him to correctly apply an incipient generalization on a far task (Figure 4) after successfully generating stages 4 and 5 (Figure 3) of his emerging pattern. In the case of the Figure 5 pattern, however, he began to experience difficulty coping with the exact nature of, and relationships between, the triangles and squares in stage 4 (Figure 6). When he constructed stages 4 and 5 with the blocks, he first built triangle borders and then added squares (lines 19 to 20). Consequently, David produced inconsistent stages that led to an incorrect generalization.

(C) 2018 by the authors; licensee Modestum Ltd., UK. This article is an open access article distributed under the terms and conditions of the Creative Commons Attribution License (http://creativecommons.org/licenses/by/4.0/). 


\section{Contribution of this paper to the literature}

- This article provides a selective synthesis of empirical research studies on pattern generalization that have been conducted with elementary school students. We focus on studies that describe the role of various cognitive factors in explaining children's pattern generalization processing involving numerical and figural patterns. To date, there is no singular or optimal path that would guarantee successful pattern generalization, leading to the possibility of multiple paths that largely depend on how they interpret various components of a given pattern (e.g., inferred shape, abduced relationships, expressed figural property, etc.).

- This article elucidates three types of inferential reasoning that are involved in the construction and justification of pattern generalization at the elementary level, namely: abduction, induction, and deductive closure. The emergence of types depend on how elementary students process the numerical and/or figural components of patterns. In cases of figural patterns, approximate and exact forms of generalization depend on their ability to establish relationships between and among the shapes, numerical relationships, and figural properties that are inferred on patterns.

- When appropriate, findings from pattern studies involving elementary school students are compared with findings drawn from patterns involving middle school students on similar tasks in order to demonstrate common and distinct ways of processing patterns, establishing structures, and forming generalizations.

These are how our stages in a pattern look like.

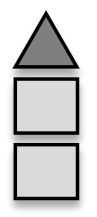

Stage 1

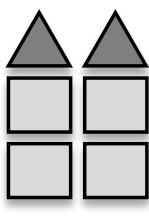

Stage 2

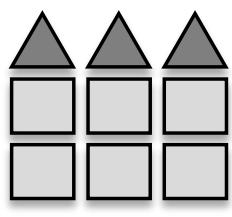

Stage 3

Figure 1. Building Houses Pattern
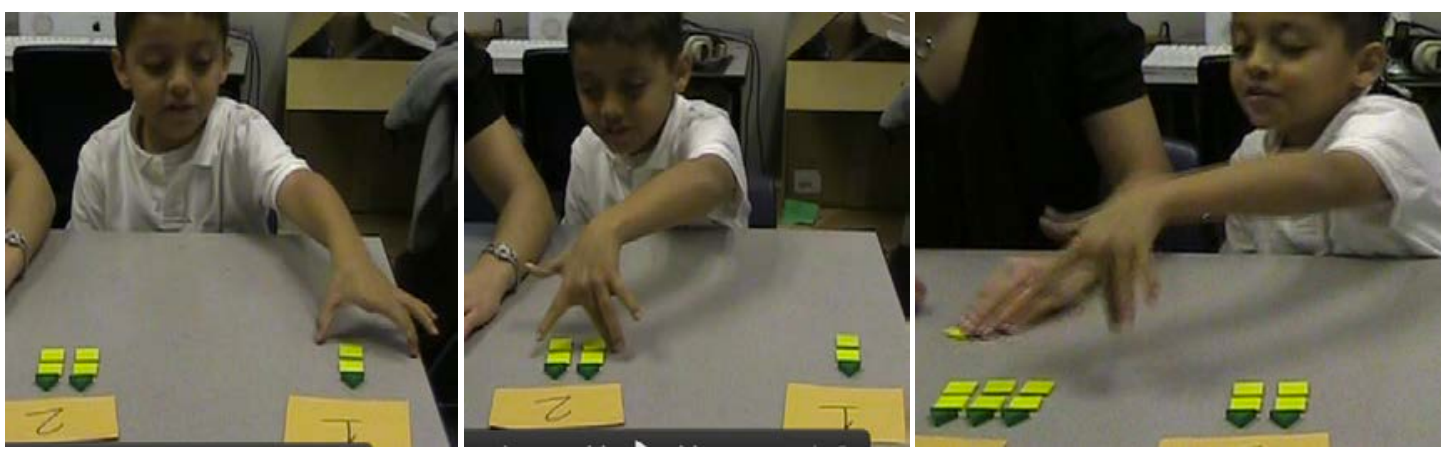

Figure 2. David's Initial Abductive Inference on the Figure 1 Pattern

1 Interviewer: David, will you show me what comes next? How does stage 4 look like with the blocks?

2 David: $\quad$ There's one of them (pointing to the whole figure in stage 1 of Figure 2). There's two

3 of them (pointing to the two full figures in stage 2). Now there's three of them (pointing

$4 \quad$ to the three full figures in stage 3).

5 Interviewer: OK, great. Can you show me what would come in stage 4? (David builds stage 4, as

$6 \quad$ shown in Figure 3) What would come next? Stage 5, build that here. (See Figure 3) 
Figure 3. David's Constructed Stages 4 and 5 of the Figure 1 Pattern

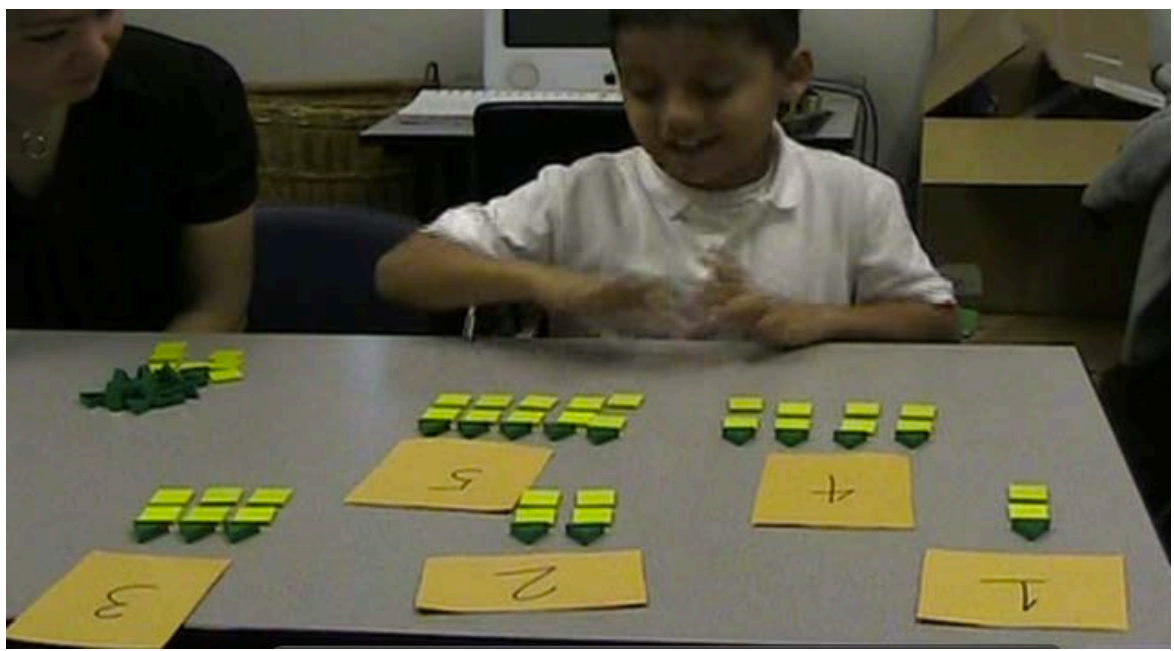

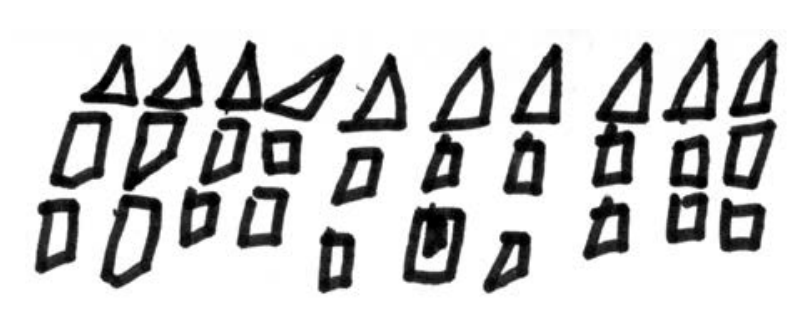

Figure 4. David's Constructed Stage 10 of the Figure 1 Pattern

Below are the stages in our pattern.

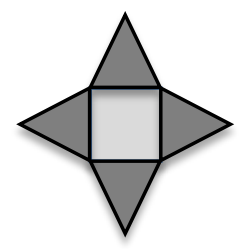

Stage 1

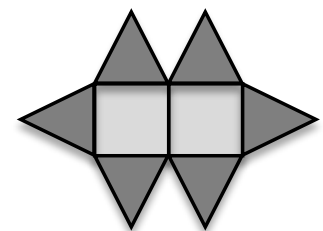

Stage 2

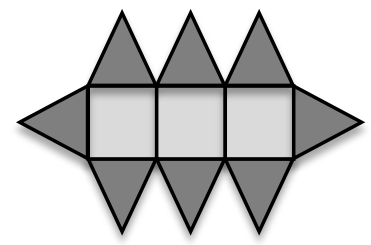

Stage 3

Figure 5. Triangular Pond Pattern

8 Interviewer: So what if we skip what comes next in stages $5,6,7,8$, and 9. We want to know what

$9 \quad$ would come next in stage 10. Can you draw with little squares and triangles what

$10 \quad$ stage 10 would look like? (David draws on paper stage 10; see Figure 4)

$11 \mathrm{I}: \quad$ Very nice.

12 Interviewer: Will you show me what comes next? How does stage 4 look like with the blocks?

13 (David gathers several pieces of triangles and squares and constructs stage 4; see

$14 \quad$ Figure 6) 


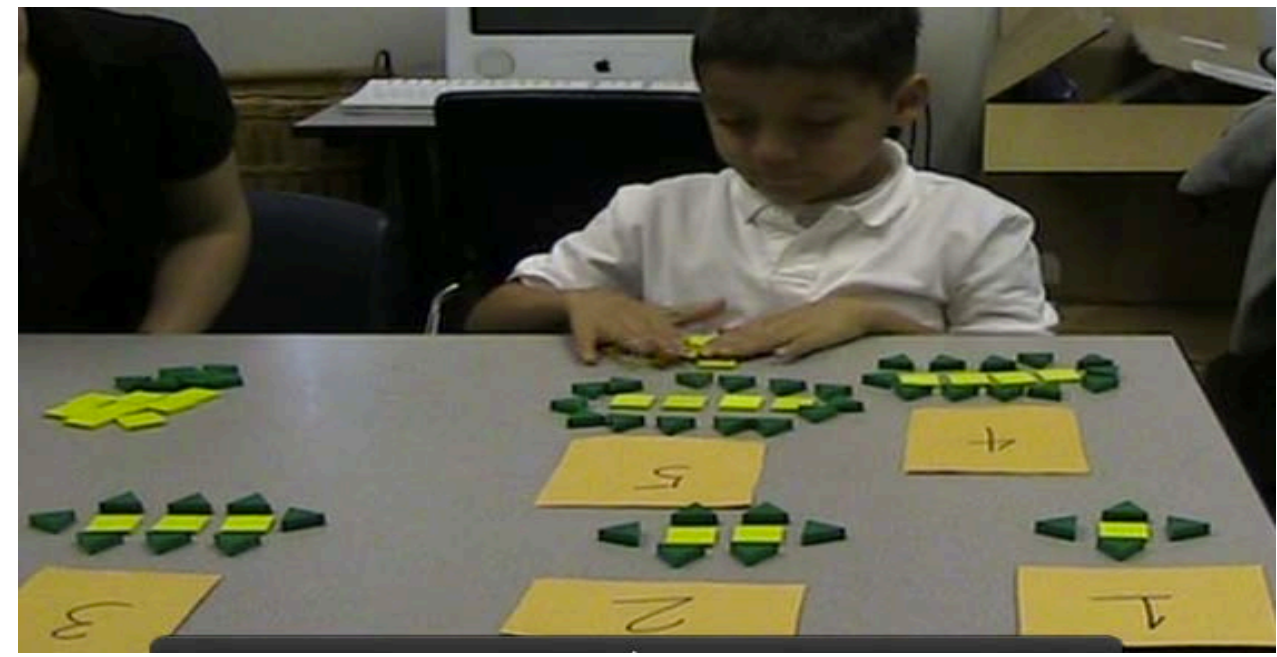

Figure 6. David's Constructed Stages 4 and 5 of the Figure 5 Pattern

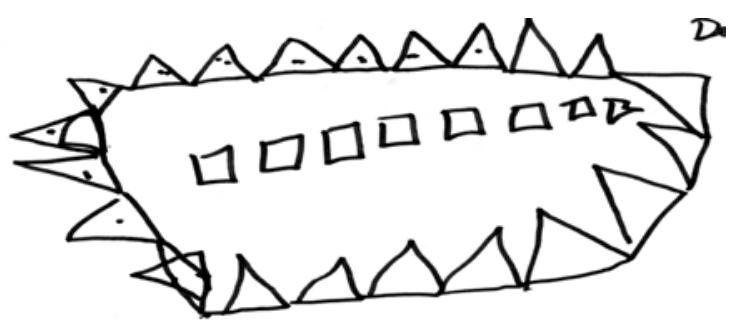

Figure 7. David's Constructed Stage 10 of the Figure 5 Pattern

15 Interviewer: Okay. Can you show me what's next? (David's stage 5 is shown in Figure 6)

16 Interviewer: Now suppose we skip steps and build stage 10. How would it look like to you?

17

(David draws his stage 10 on paper; see Figure 7)

18 Interviewer: Okay can you explain to me how you knew what to do?

19 David: $\quad$ Because I kinda copy these (points to stage 3) because the triangles were like kinda

20 surrounding these little squares so that I have these (referring to his stage 10).

21 Interviewer: How'd you know how many squares to put there?

22 David: Because I wanted them to fit in.

23 Interviewer: Okay, great.

David's thinking about the Figure 5 pattern had a happy ending, of course. During the final clinical interview, which took place after an intervening teaching experiment on patterns, he once again dealt with the same two pattern generalization tasks. In the case of Figure 5, he initially employed gestures (Figure 8) when he pointed out what he interpreted to be three invariant parts that comprised every stage in his pattern (lines 25-28). Furthermore, because he applied the same set of gestures repeatedly over several more stages, which we will call action or reasoning by induction, it enabled him to produce a consistent pattern generalization for far stages 10,25 , and 100 that he conveyed rhythmically in verbal form without needing to draw each one (lines 33-40). We will call this successful transfer on far stages reasoning by deductive closure. 


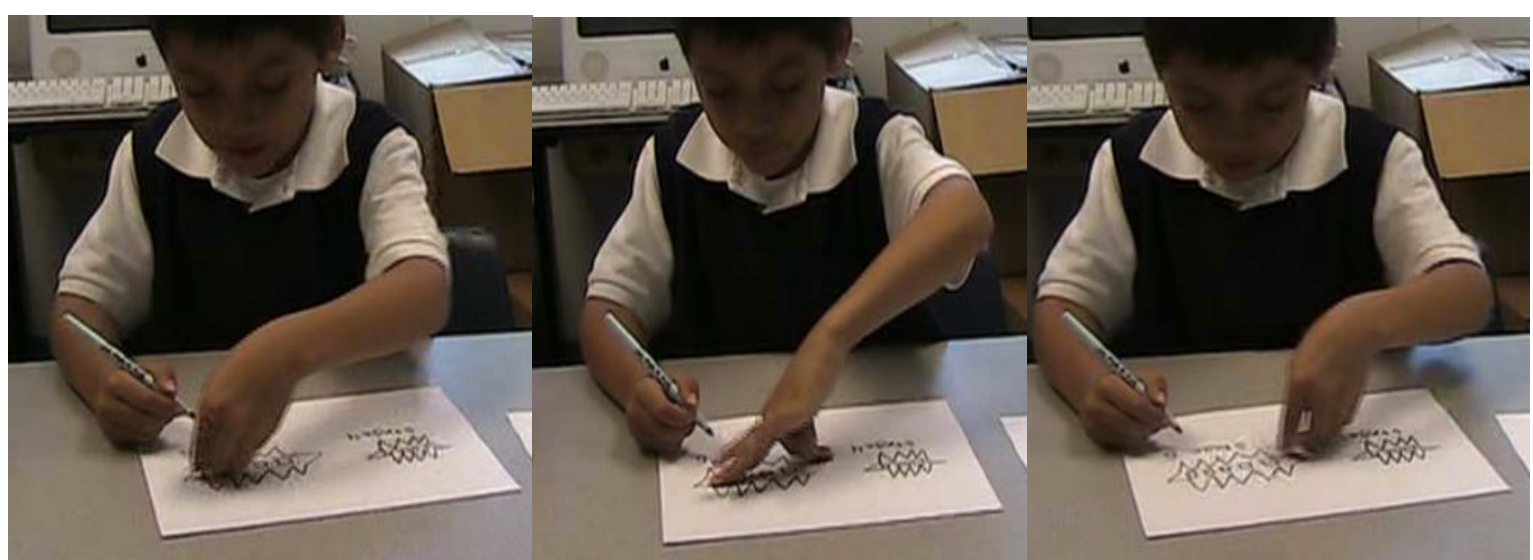

Figure 8. David's Gesture-Driven Description of Stage 5 Relative to the Figure 5 Pattern

24 Interviewer: Okay how did you know what to draw?

25 David: Because here [stage 4], this one has 4 [squares], and 4 triangles [on top], and 2

26 [triangles] on the sides, and 4 Figs. [bottom triangles]. And this one [stage 5], it's

27 supposed to have 5 triangles [top row], 2 [triangles] on the sides, and 5 [triangles]

28 right here [bottom row]. (See Figure 8)

29 Interviewer: And what did you put in the middle?

30 David: $\quad$ These are ducks.

31 Interviewer: Oh, so are these squares?

32 David: Yeah.

33 Interviewer: Okay, so what about stage 10. Can you explain what it would have?

34 David: It would have 10 triangles on the top and on the bottom, 2 triangles on the sides, and

35 and 10 squares in the middle.

36 Interviewer: Okay, and what about stage 25?

37 David: $\quad 25$ triangles on the top, 25 triangles on the bottom, 2 triangles on the sides, and 25

38 squares in the middle.

39 Interviewer: What about stage 100 ?

40 David: 100 triangles on the top, 100 triangles on the bottom, 2 triangles on the sides, and 100

41 squares in the middle.

In this article, we focus on pattern generalization studies that have been conducted with elementary school children from Grades 1 through 5 (ages 6 through 10 years) in different contexts across different countries. We also draw quite significantly on the author's longitudinal studies with intact classes of US Grades 2 and 3 students when we need to illustrate particular research findings. The fundamental aim in this article is to elucidate cognitive factors that influence the development of mathematical structures and incipient generalizations in elementary school children on the basis of their work on patterns, including how they use various representational forms such as gestures, words, and arithmetical symbols to convey their expressions of generality.

In the next seven sections, we pursue different aspects of pattern generalization processing that matter to elementary school children. In section 1, we describe approximate and exact pattern generalizations. Sections 2 to 4 describe three major cognitive factors that shape the emergence of mathematical structures, namely, competence with number relationships, competence with shape, and competence with figural property construction. These factors require different forms of abductive actions that elementary students need to coordinate successfully together in order to construct, induce, deductively close, and justify an algebraically useful exact generalization. In section 5, we focus on representational modes that elementary students oftentimes use to capture their emergent structures and incipient generalizations, which are based on their initial stipulated abductions about their patterns. These modes include gestural, pictorial, verbal, and numerical. In section 6, we address grade-level appropriate use and understanding of variables via the notions of intuited and tacit variables. In section 7, we analyze the relationship between elementary children's structural incipient generalizations and the natural emergence of their understanding of functions, especially the central role of abduction in such an understanding. 


\section{APPROXIMATE AND EXACT GENERALIZATIONS}

David's stage 10 figures in Figures 4 and 7 exemplify explicit responses that model exact and approximate generalizations, respectively. In Figure 7, an approximate incipient generalization, he constructed and established stage 10 by inferring shapes that were similar in form. He abduced what he interpreted to be the pertinent figural characteristics across the given stages in order to inductively process stages 4, 5, and 10 of his emerging pattern. However, he inconsistently counted the number of squares and triangles from stage 4 and up. Approximate generalizations $(A G)$ are fuzzy generalities of an emergent structure, that is, the three aspects of number, shape, and figural properties are not well coordinated in a harmonious and consistent or stable manner.

Figure 4 exemplifies an exact incipient generalization. David abduced stage 10 to have 10 sets of the same figural unit (a triangle and two squares). He also inferred growth along the same horizontal direction consistent with the three given stages in the pattern. Exact generalizations $(E G)$ are conceptually consistent generalities of an emergent structure, that is, the three aspects of number, shape, and figural properties are well coordinated in a harmonious and consistent or stable manner.

Several recent pattern generalization studies conducted with elementary school students confirm the prevalence of the two types of incipient generalizations (e.g.: Blanton et al., 2015; Walkowiak, 2014; Wilkie, 2014; Wilkie \& Clarke, 2016; Whitin, P. \& Whitin, D., 2011). Furthermore, these studies demonstrate the following observations below.

- Choosing between AG or EG seems to depend on task complexity, which means pattern generalizing relies on how individual learners perceive, interpret, and construct the structural complexity of a set of stages in a pattern. Pattern generalizing could also be task-induced, meaning it could be driven by the causal potency of the given stages.

- Factors such as novelty of task, weak prior knowledge, and disposition at the moment of generalizing may influence the content of elementary students' generalizations.

- Different levels of AG exist, which can be distinguished according to conceptual competencies in the three aspects of number, shape, and figural property discernment. We discuss each aspect in detail in the following three sections below.

\section{COMPETENCE WITH NUMBERS AND NUMBER RELATIONSHIPS}

Typically developing elementary students have number sense. In fact, the most significant finding in neuroscientific research involving children's natural numeric competence is the approximate nature in which they exhibit number sense early in their experiences (Dehaene, 1997), which under normal circumstances transition to (adult) exact understanding with more social and cultural learning. There is no permanent shift, of course, as adults in neuroimaging experiments still appear to activate the regions of their parietal lobe that are oftentimes associated with approximate number processing when they perform mental calculations (Pinel, Dehaene, Riviere, \& LeBihan, 2001). Changes in numeric processing from approximate to exact counting are primarily mediated by language, and developmental research has consistently documented young children's initial difficulties in learning their correct meanings following adult practices (Condry \& Spelke, 2008; Le Corre \& Carey, 2007; Lipton \& Spelke, 2005). Some children, for example, do not map the correct number word for a set of concrete objects, while other children can recite the number words rather proficiently but then fail to grasp their meanings.

Considering the implications of the above findings on elementary children's developing skills in exact numerical processing, Rivera (2010) assessed the nature of second grade students' pre-instructional competence on the two numerical pattern generalization tasks shown in Figures 9 and 10. Twenty-one US Grade 2 students (ages 7 to 8 years; 7 girls and 14 boys; 20 Hispanic-Americans and 1 African-American) each participated in two clinical interview sessions in which they dealt with the Figures $\mathbf{9}$ and $\mathbf{1 0}$ tasks two times. Each numerical patterning task involves five to six near generalization items (i.e. stages 1 through 6 ), one to two far generalization items (i.e. stages 10 and 20), and an inversion problem (i.e. determine the stage number or input for a given total or output). The first clinical interviews took place six weeks after the start of classes, while the second interviews occurred six weeks after the first interviews. During the first interview, the students were provided with a construction pad and a number line of whole numbers from 0 to 100. Since the author anticipated that some students would exhibit conceptual difficulties with exact counting as noted in the above paragraph, the number line offered them additional support in case they needed to use it for counting-related purposes. During the second interview, both construction pad and number line were available. Furthermore, due to the students' difficulties with the inversion problems during the first interview, sheets containing pictures of dog eyes and zebra legs were made available for them to use as well. 


\begin{abstract}
Number of Dog Eyes
Here is 1 dog puppet on the table. How many eyes does one dog have?

Here are 2 dog puppets. How many eyes do 2 dogs have? How do you know? Can you explain it to me?

Here are 3 dog puppets. How many eyes do 3 dogs have? How do you know? Can you explain it to me?

We only have three dog puppets on the table. So you need to imagine more dogs in your head.

A. How many eyes do 4 dogs have? How do you know for sure? Can you tell me how you're thinking about it?

B. How many eyes do 5 dogs have? Can you tell me how you're thinking about it?

C. How many eyes do 10 dogs have? Can you tell me or show me on paper how you're thinking about it?

D. How many eyes do 20 dogs have? Can you tell me or show me on paper how you're thinking about it?

E. A normal dog has two eyes. How many dogs are there with a total of 17 eyes? Can you tell me or show me on paper how you're thinking about it?
\end{abstract}

Figure 9. Number of Dog Ears Pattern Generalization Task for Grade 2 Students

Number of Zebra Legs

Here is 1 zebra toy. How many legs does one zebra have?

Here are 2 zebra toys. How many legs do 2 zebras have? Can you show me how you know so?

Here are 3 zebra toys. How many legs do 3 zebras have? How do you know?

We only have three zebra toys on the table. So you need to imagine more zebras in your head.

A. How many legs do 4 zebras have? How do you know for sure? Can you tell me how you're thinking about it?

B. How many legs do 5 zebras have? How do you know for sure? Can you tell me or show me on paper how you're thinking about it?

C. How many legs do 10 zebras have? How do you know for sure? Can you tell me or show me on paper how you're thinking about it?

D. How many legs do 20 zebras have? How do you know for sure? Can you tell me or show me on paper how you're thinking about it?

E. A normal zebra has four legs. How many zebras are there with a total of 21 legs? Can you tell me or show me on paper how you're thinking about it?

Figure 10. Number of Zebra Legs Pattern Generalization Task for Grade 2 Students

Tables 1 and 2 provide summaries of the results drawn from the first clinical interviews with respect to the two numerical pattern generalization tasks shown in Figures 9 and 10. More than half of the students initially engaged in perceptual subitizing ( 2 to 4 objects) in dealing with stage 1 . Then a conceptual shift toward the use of a countingall strategy took place when the students obtained the total number of the objects in stage 2 for each pattern. Furthermore, the same counting-all strategy was more frequently used than the other arithmetical strategies when it came time to processing the remaining near generalization tasks (stages 3 through 6). As shown in the two tables, the other arithmetical strategies were counting on, skip counting by 2 and 4 , and using the doubles facts (e.g. " $2+$

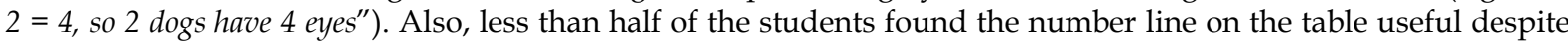
the consistent reminder from the interviewer that it could be used at all times.

When the students dealt with the far generalization tasks (stages 10 and 20), at least two-thirds of them shifted to approximate processing, which explains the very low percentage of correct responses on the two tasks (about $22 \%$ for the dog eyes pattern and about $10 \%$ in the case of the zebra legs pattern). Examples of students' approximate values for stages 10 and 20 for the Figure 9 pattern are 24 and 32, respectively. For the Figure 10 pattern, approximate values for stages 10 and 20 are 30 and 42, respectively. Almost all of the students who suggested incorrect approximate values for the far stages offered numbers that they thought were reasonable. One student, for example, suggested 42 legs for far stage 20 of the zebra legs pattern and said, "I just know in my head that it is a lot." There were also a handful of other incorrect responses that involve adding the sum of the last known total count on a near generalization task (stage 5 or 6 ) and the targeted far generalization stage number. For example, one student argued that since "there are 12 eyes that I counted for stage 6 [in Figure 9]," then "stage 10 has 22 eyes [since $12+10=22]$." Finally, the students found the inverse tasks very difficult to process with only one student on each task able to explicitly articulate a reasonable answer ("there are 8 and a half dogs," "there are 5 zebras and another one with just one leg"). The primary source of difficulty was language with a majority of them confusing input numbers and output values. About one-third of them initially drew the required number of objects corresponding to the output value using sticks and circles. Unfortunately, they did not know how to proceed further (e.g., grouping the drawn figures by two or by four) and eventually gave up. 
Table 1. Grade 2 Students' First Round Interview Results on the Figure 9 Patterning Task ( $n=21$; *Drew 19 circles first.)

\begin{tabular}{|c|c|c|c|c|c|c|c|c|c|c|}
\hline Subtasks & $\begin{array}{l}\text { Perceptual } \\
\text { Subitizing }\end{array}$ & $\begin{array}{c}\begin{array}{c}\text { Counting All } \\
\text { without } \\
\text { Number } \\
\text { Line }\end{array} \\
\end{array}$ & $\begin{array}{l}\text { Counting } \\
\text { All with } \\
\text { Number } \\
\text { Line }\end{array}$ & $\begin{array}{c}\text { Counting } \\
\text { On without } \\
\text { Number } \\
\text { Line } \\
\end{array}$ & $\begin{array}{c}\text { Counting } \\
\text { On with } \\
\text { Number } \\
\text { Line }\end{array}$ & $\begin{array}{c}\text { Skip Counting } \\
\text { by } 2 \\
\text { without } \\
\text { Number Line } \\
\end{array}$ & $\begin{array}{l}\text { Skip Counting } \\
\text { by } 2 \text { with } \\
\text { Number Line }\end{array}$ & $\begin{array}{l}\text { Using } \\
\text { Doubles } \\
\text { Facts }\end{array}$ & $\begin{array}{l}\text { Could } \\
\text { Not Do }\end{array}$ & $\begin{array}{c}\text { Initial } \\
\text { Struggle } \\
\text { Stage }\end{array}$ \\
\hline NG Stage 1 & 20 & 1 & & & & & & & & \\
\hline NG Stage 2 & 2 & 12 & & & & & & 7 & & \\
\hline NG Stage 3 & & 14 & & 1 & & 4 & & 2 & & \\
\hline NG Stage 4 & & 7 & 5 & 2 & & 2 & & 2 & 3 & 2 \\
\hline NG Stage 5 & & 1 & 10 & 1 & & 2 & 2 & 1 & 4 & 6 \\
\hline NG Stage 6 & & 3 & 1 & 1 & 5 & 3 & & & 8 & 2 \\
\hline FG Stage 10 & & & & 1 & & 3 & 2 & 1 & 14 & 4 \\
\hline FG Stage 20 & & & & & & 1 & 1 & 1 & 18 & 1 \\
\hline Inverse & & & & & & $1^{*}$ & & & 20 & \\
\hline
\end{tabular}

Table 2. Grade 2 Students' First Round Interview Results on the Figure 10 Patterning Task $(n=21)$

\begin{tabular}{|c|c|c|c|c|c|c|c|c|c|}
\hline Subtasks & $\begin{array}{l}\text { Perceptual } \\
\text { Subitizing }\end{array}$ & $\begin{array}{c}\text { Counting All } \\
\text { without } \\
\text { Number Line }\end{array}$ & $\begin{array}{c}\text { Counting On } \\
\text { without } \\
\text { Number Line }\end{array}$ & $\begin{array}{l}\text { Counting } \\
\text { On with } \\
\text { Number } \\
\text { Line }\end{array}$ & $\begin{array}{c}\text { Skip Counting } \\
\text { by } 2 \\
\text { without } \\
\text { Number Line }\end{array}$ & $\begin{array}{l}\text { Combined Counting } \\
\text { All and Counting On } \\
\text { with Number Line }\end{array}$ & $\begin{array}{c}\text { Drew Sticks } \\
\text { and } \\
\text { Grouped by } \\
4 \\
\end{array}$ & $\begin{array}{l}\text { Could } \\
\text { Not Do }\end{array}$ & $\begin{array}{c}\text { Initial } \\
\text { Struggle } \\
\text { Stage }\end{array}$ \\
\hline NG Stage 1 & 12 & 8 & 1 & & & & & & \\
\hline NG Stage 2 & & 15 & 4 & & 1 & & & 1 & 1 \\
\hline NG Stage 3 & & 13 & 5 & & & & & 3 & \\
\hline NG Stage 4 & & 11 & 6 & 1 & & & & 3 & 2 \\
\hline NG Stage 5 & & 8 & 4 & 1 & & & & 8 & 5 \\
\hline \multicolumn{10}{|l|}{ NG Stage 6} \\
\hline FG Stage 10 & & & & & & 2 & & 19 & 2 \\
\hline FG Stage 20 & & & & & & & & 21 & \\
\hline Inverse & & & & & & & 1 & 20 & \\
\hline
\end{tabular}

Tables 3 and 4 provide summaries of the results drawn from the second clinical interviews with respect to the two patterns shown in Figures 9 and 10. None of the students used the number line on the table to help them count. Perceptual subitizing was evident when the students initially attended to stage 1 in both patterns. In dealing with the near generalization tasks beyond stage 2, there was a noticeable use of other arithmetical strategies beyond counting all. Furthermore, about one-third of the students successfully dealt with the far generalization tasks. Sources of support on these tasks were the intensive classroom learning and instruction in exact number sense and the student-generated diagrams (i.e. sticks and circles) during the interview session that enabled them to count correctly and obtain the correct values. Figure 11 illustrates how two students drew diagrams to help them monitor their counting processes and remember the numbers that they already counted. Nikki on the left drew 10 pairs of circles corresponding to stage 10 of the Figure 9 pattern that enabled her to count to 20. Skype on the right obtained the same final value as Nikki but in his case he drew 10 circles and filled them one by one with numbers that corresponded to consecutive multiples of 2. Finally, while the inverse tasks continued to be difficult for most students despite the availability of drawn pictures of dog eyes and zebra legs, those who successfully processed them grouped each picture set either by 2 or by 4 . Figure 12 shows two examples of student work on the inverse task involving the Figure 10 pattern. David on the left circled sets of 4 legs that enabled him to conclude that 7 zebras had 28 legs in all. Manny on the right initially labeled all the square pictures with consecutive numbers from 1 to 4 . He then noted that since there were 7 groups of consecutive numbers from 1 to 4 , there were 7 zebras with 28 legs altogether.

Table 3. Grade 2 Students' Second Round Interview Results on the Figure 9 Patterning Task $(n=19)$

\begin{tabular}{|c|c|c|c|c|c|c|c|c|c|}
\hline Subtasks & $\begin{array}{l}\text { Perceptual } \\
\text { Subitizing }\end{array}$ & $\begin{array}{c}\text { Counting All } \\
\text { without } \\
\text { Number Line } \\
\end{array}$ & $\begin{array}{c}\text { Counting On } \\
\text { without } \\
\text { Number Line } \\
\end{array}$ & $\begin{array}{c}\text { Skip Counting by } 2 \\
\text { without Number } \\
\text { Line }\end{array}$ & $\begin{array}{c}\text { Using } \\
\text { Doubles } \\
\text { Facts } \\
\end{array}$ & $\begin{array}{c}\text { Skip } \\
\text { Counting } \\
\text { by } 10 \\
\end{array}$ & $\begin{array}{c}\text { Grouped } \\
\text { by } 2\end{array}$ & $\begin{array}{c}\text { Could } \\
\text { Not Do }\end{array}$ & $\begin{array}{c}\text { Initial } \\
\text { Struggle } \\
\text { Stage } \\
\end{array}$ \\
\hline NG Stage 1 & 17 & 2 & & & & & & & \\
\hline NG Stage 2 & 2 & 7 & 2 & 7 & 1 & & & & \\
\hline NG Stage 3 & & 7 & 2 & 9 & 1 & & & & \\
\hline NG Stage 4 & & 7 & 3 & 6 & 1 & & & 2 & 3 \\
\hline NG Stage 5 & & 9 & 3 & 6 & 1 & & & & 1 \\
\hline \multicolumn{10}{|l|}{ NG Stage 6} \\
\hline FG Stage 10 & & 1 & 2 & 8 & & 1 & & 7 & 6 \\
\hline FG Stage 20 & & & & 1 & 1 & & & 17 & \\
\hline Inverse & & & & & & & 6 & 13 & \\
\hline
\end{tabular}


Table 4. Grade 2 Students' Second Round Interview Results on the Figure 10 Patterning Task $(n=19)$

\begin{tabular}{|c|c|c|c|c|c|c|c|c|c|}
\hline Subtasks & $\begin{array}{l}\text { Perceptual } \\
\text { Subitizing }\end{array}$ & $\begin{array}{c}\text { Counting All } \\
\text { without } \\
\text { Number Line }\end{array}$ & $\begin{array}{c}\text { Counting On } \\
\text { without } \\
\text { Number Line }\end{array}$ & $\begin{array}{c}\text { Skip Counting by } 4 \\
\text { without Number } \\
\text { Line }\end{array}$ & $\begin{array}{l}\text { Using } \\
\text { Doubles } \\
\text { Facts }\end{array}$ & $\begin{array}{c}\text { Skip } \\
\text { Counting } \\
\text { by } 2 \\
\end{array}$ & $\begin{array}{l}\text { Grouped } \\
\text { by } 4\end{array}$ & $\begin{array}{l}\text { Could } \\
\text { Not Do }\end{array}$ & $\begin{array}{c}\text { Initial } \\
\text { Struggle } \\
\text { Stage }\end{array}$ \\
\hline NG Stage 1 & 14 & 5 & & & & & & & \\
\hline NG Stage 2 & 2 & 6 & 7 & 2 & 2 & & & & \\
\hline NG Stage 3 & & 11 & 7 & 1 & & & & & \\
\hline NG Stage 4 & & 9 & 8 & 1 & & 1 & & & \\
\hline NG Stage 5 & & 8 & 8 & 1 & & & & 2 & 2 \\
\hline \multicolumn{10}{|l|}{ NG Stage 6} \\
\hline FG Stage 10 & & 1 & 3 & 1 & & & 1 & 14 & 1 \\
\hline \multicolumn{10}{|l|}{ FG Stage 20} \\
\hline Inverse & & & & & & & 5 & 14 & \\
\hline
\end{tabular}
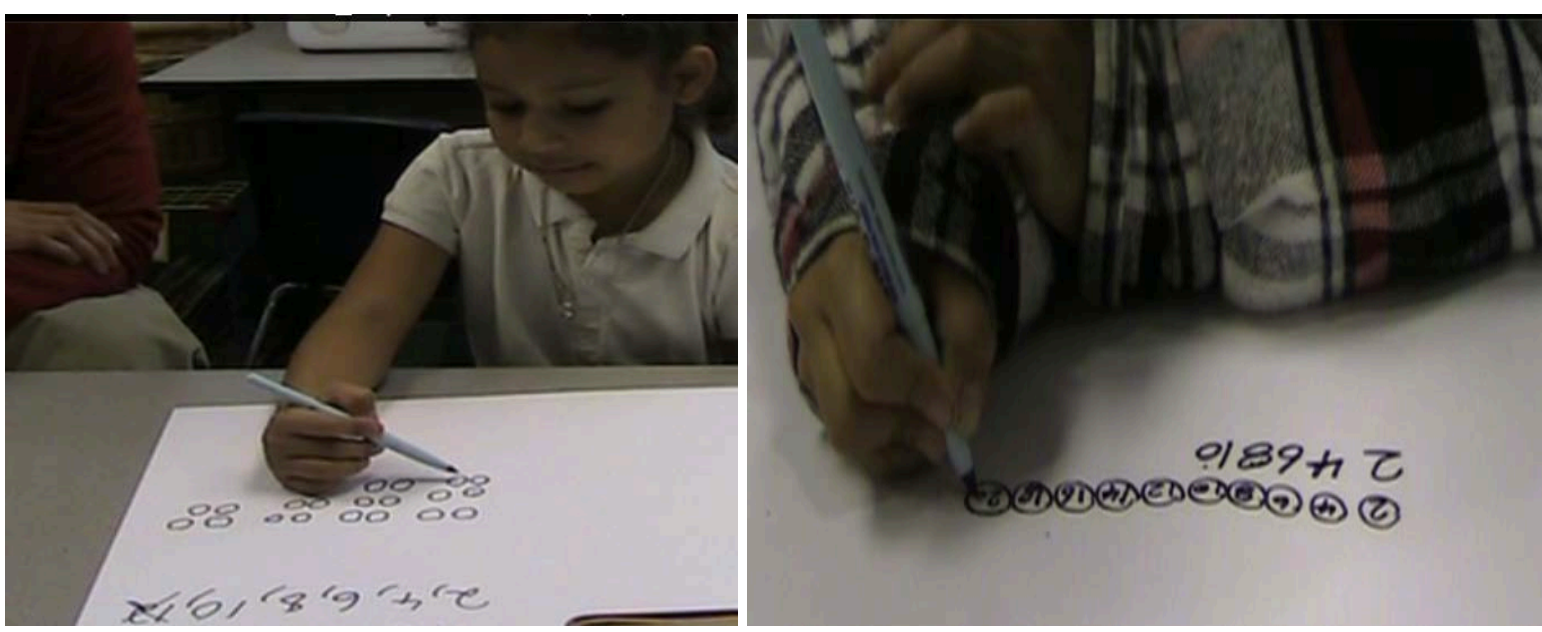

Figure 11. Second Grade Student-Generated Diagrams in Dealing with Far Generalization Tasks
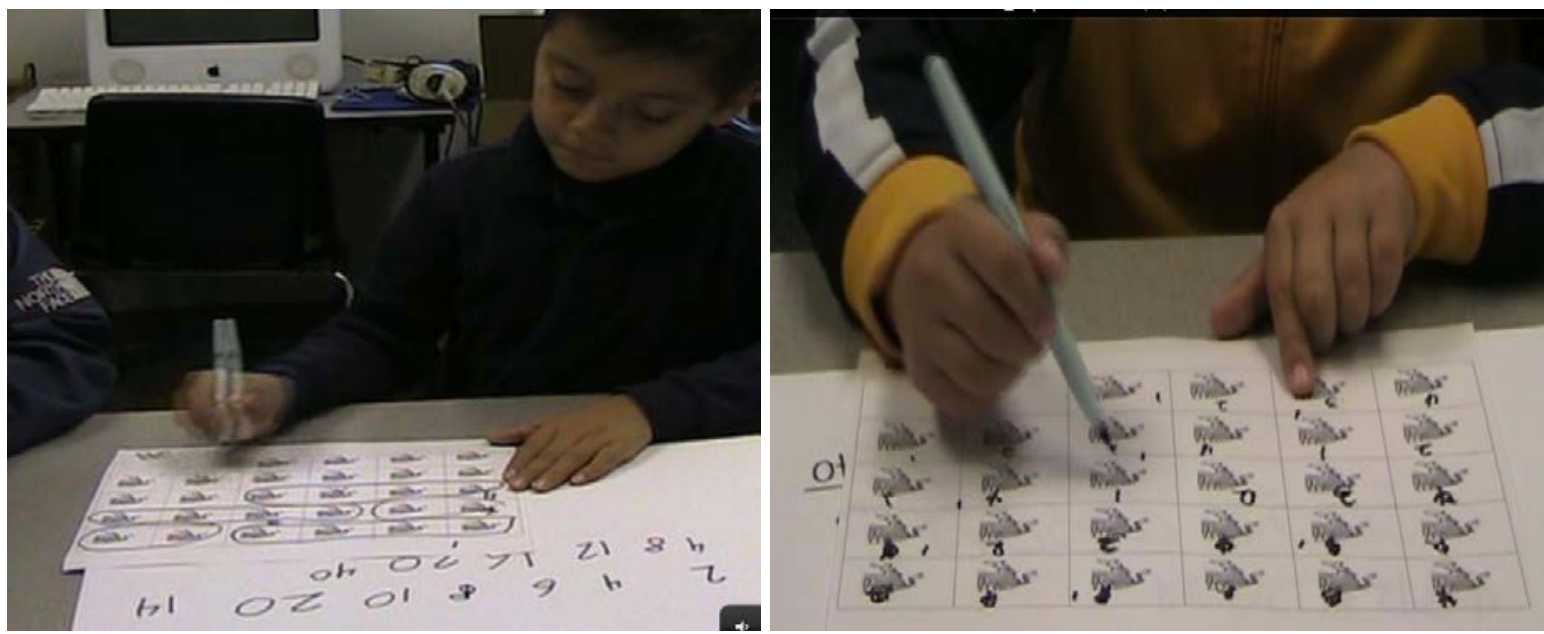

Figure 12. Second Grade Student-Generated Methods in Dealing with an Inverse Task

The development of different arithmetical strategies plays a significant role in students' pattern generalization processing, in particular, at the upper elementary levels when numbers taken as input units need to be interpreted in the context of a mathematical relationship. For the numerical patterns shown in Figures 9 and 10, the prevalent use of a counting-all arithmetical strategy on both tasks in the two interview sessions distracted a majority of the second grade students from establishing more meaningful invariant structural relationships.

Even with a noticeable shift toward the use of counting on, double facts, and skip counting strategies during the second interview, the students needed additional training in interpreting them as instantiating particular structural relationships within and across the given input units. For example, when Lina was asked to explain her double fact $3+3=6$ that led her to conclude that 3 normal dogs had 6 eyes altogether, she said, "I first counted 3 [eyes] here [pointing to the three left eyes] and then I counted 3 more [eyes] here [pointing to the right eyes]." In dealing with 
Tom is $\mathbf{4}$ inches taller than Maria. Maria is 6 inches shorter than Leslie. Draw Tom's height, Maria's height, and Leslie's height. Show what the numbers 4 and 6 refer to.

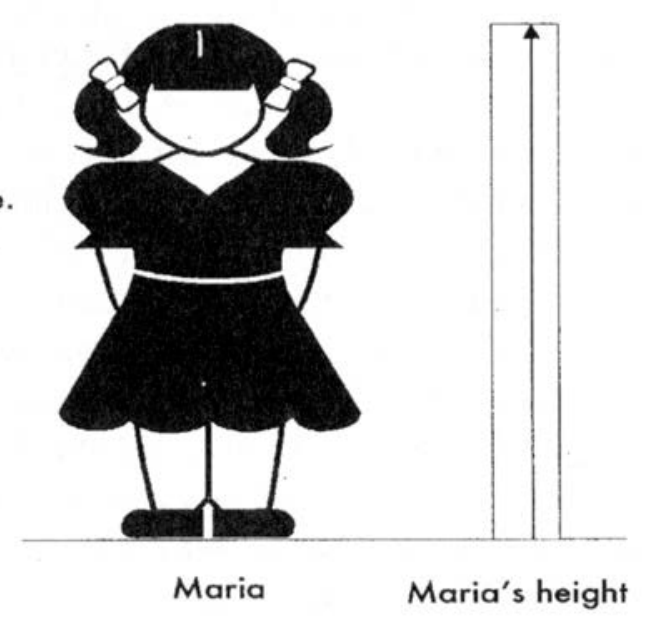

Figure 13. Additive Comparison Task (Carraher, Schliemann, Brizuela, \& Earnest, 2007, p. 72)

4, 5, and 10 dogs, however, she changed her arithmetical strategy and employed combinations of counting-all and count-on strategies that still enabled her to obtain the correct output values without needing to pay attention to possible mathematical relationships that she could have abduced from the strategies. In fact, none of the students employed the same arithmetical strategy consistently within and across the input units of the two patterns, which partly explains why they experienced considerable difficulty in dealing with the far generalization tasks. Also, the presence of several different choices, the lack of metacognitive strategies such as perceptual agility, and the need to stay consistent from subtask to subtask in arithmetical processing prevented them from establishing meaningful incipient generalizations that would have worked for all far generalization tasks. Lee (1996) poignantly surfaces the central role of perceptual agility in pattern generalization, which involves "see[ing] several patterns and [a] willing[ness] to abandon those that do not prove useful [i.e. those that do not lead to a direct formula]" (p. 95).

Several recent research investigations that have been conducted with other groups of elementary (and middle) school students on number patterns have also articulated similar issues. Carpenter and Levi's (2000) studies with small groups of first- and second-grade students on true-false number sentences and open number sentences assessed their ability to think about properties of number operations, including the evidence and rules they employed to justify their generalizations. They note how many of the students "experienced difficulty" in developing explanations "that went beyond examples, although a number of students did recognize the necessity of more generalizable justifications" (p. 16). Central to the noted difficulty was the lack of a more sophisticated understanding of the equal symbol (i.e. the relation/product issue) and appropriate notational systems for conveying, and rules for justifying, general explanations. Carraher, Schliemann, Brizuela, and Earnest's (2006) work with third-grade students in relation to the additive comparison task shown in Figure $\mathbf{1 3}$ highlights the students' conceptual difficulties with mathematical language. Several students, for example, confused between the terms "taller" and "tall" and "shorter" and "short." It was only when the class as a whole unit reenacted the problem with three volunteers that the students came to understand the relational terms. Also, even when the students managed to generate correct values for the problem and illustrate their relationships with a diagram, there were still a few others who "remained hesitant about what region of their diagram corresponded to the values [4 inches and 6 inches]" (Carraher, Schliemann, \& Brizuela, 1999, p. 2). Figure 14 illustrates samples of two students' work on the Figure 13 task, which could be interpreted as a number pattern generalization task. Continuous engagement with particular instances (i.e. story situations) enabled the students to engage in mutual abduction and induction that eventually enabled them to establish a structural argument in the form of variable expressions (i.e., $T, T-4$, and $T+2)$. 


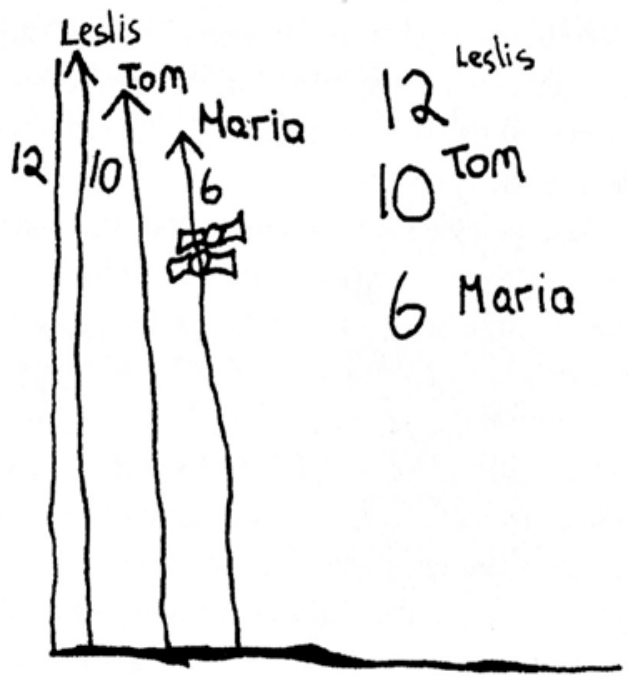

Tom is 4 inches taller than Maria.

Maria is 6 inches shorter than Leslie.

Fill out the table for Story 1.

Imagine Tom is 34 inches tall. How tall will Maria and Leslie be?

\begin{tabular}{|c|c|c|}
\hline What if... & Tom & Maria \\
\hline Story 1 & 34 in. & $30 \mathrm{in} .36 \mathrm{ln}$. \\
\hline Story 2 & 37 in. & 33 in 39 in \\
\hline Story 3 & 4 lii & 37 in. 43 in. \\
\hline Story 4 & & $3 /$ in. 37 in. \\
\hline Story 5 & & $t+2$ \\
\hline
\end{tabular}

Then work out the answers for Stories 2,3 , and 4 .

Figure 14. Samples of Student Work on the Figure 13 Problem (Carraher, Schliemann, Brizuela, \& Earnest, 2007, pp. 74 \& 76)

\begin{tabular}{|c|c|}
\hline \multicolumn{2}{|c|}{ (a) } \\
\hline Boxes of Cookies & Price \\
\hline 1 & \\
\hline 2 & $\$ 6.00$ \\
\hline 3 & $\$ 9.00$ \\
\hline 4 & $\$ 12.00$ \\
\hline & $\$ 15.00$ \\
\hline 7 & $\$ 18.00$ \\
\hline 8 & $\$ 21.00$ \\
\hline 9 & \\
\hline 10 & $\$ 27.00$ \\
\hline $\mathrm{N}$ & $\$ 30.00$ \\
\hline
\end{tabular}

\begin{tabular}{|c|l|}
\hline \multicolumn{2}{|c}{$(\mathrm{b})$} \\
\hline 1 & \\
\hline 2 & \\
\hline 3 & \\
\hline 4 & \\
\hline 5 & \\
\hline & \\
\hline 7 & \\
\hline 8 & \\
\hline 9 & \\
\hline 10 & \\
\hline 20 & \\
\hline 30 & \\
\hline 100 & \\
\hline $\mathrm{N}$ & \\
\hline & \\
\hline
\end{tabular}

Figure 15. Function Tables (Schliemann, Carraher, \& Brizuela, 2007)

Schliemann, Carraher, and Brizuela's (2007) work with third-grade students on function tables involving number relationships articulates the necessity of building meanings drawn from everyday contexts: "(W)hat makes everyday contexts powerful is not the concreteness of the objects or the realism of the situations dealt with in everyday life, but the meaning attached to the problems under consideration" (p. 103). For example, they used multiplication tables in introducing the students to functional understanding involving inputs and outputs. The students learned how to fill function tables such as the one shown on the left in Figure $\mathbf{1 5}$ in the context of a certain Mary who relied on an incomplete table with prices to help her sell cookies. Over the course of the classroom teaching experiment involving function tables, the students obtained different rules that related the output values with the input terms. Interestingly enough, the conversations shifted from the use of additive strategies (e.g. "add 6 to 2," "add 2, plus 2, plus 2" in the case of the table on the left in Figure 15) to multiplicative generalizations that conveyed direct proportional relationships (e.g. $3 n$ or $n \times 3$ in relation to the table on the left of Figure 15) to closed expressions that reflected the structure of a general linear function (e.g. $n \times 2+1$ in the case of the table on the right in Figure 15). The problems also transitioned from everyday situations to more decontextualized contexts.

Carpenter, Franke, and Levi's (2003) work with elementary school children on numeric-based pattern generalization and arithmetical thinking underscore the significance of relational thinking beyond calculating results. For example, second-grade Emma in their study initially thought about adding 28 and 32 and then counting on from 27 in order to solve the number sentence $28+32=27+\ldots$. This computational process was consistent with her early experiences involving smaller numbers such as $7+\overline{6}=\ldots+5$. However, her thinking transitioned relationally when she established a relationship between the two expressions, as follows: "I think maybe 33 [is the answer] ... because 27 is one less than 28 and then 33 is one more than 32." Numeric-based pattern generalizing that 
Ricardo has 7 pet mice. He keeps them in two cages that are connected so that the mice can go back and forth between the cages. One of the cages is big and other one is small. Show all the ways that 7 mice can be in two cages.

Figure 16. Mouse-Cage Patterning Task (Carpenter, Franke, \& Levi, 2003)

\begin{tabular}{|c|c|}
\hline Big Cage & Small Cage \\
\hline 1 & 6 \\
\hline 2 & 5 \\
\hline 3 & 4 \\
\hline 4 & 3 \\
\hline 5 & 2 \\
\hline 6 & 1 \\
\hline 7 & 0 \\
\hline 0 & 7 \\
\hline
\end{tabular}

Figure 17. Second Grade Marsha's List for the Figure 16 Pattern (Carpenter, Franke, \& Levi, 2003)

fosters relational thinking in Carpenter, Franke, and Levi's sense further supports growth in structural thinking and justification. For example, when the second-grade students in Carpenter, Franke, and Levi's (2003) study dealt with the Mouse-Cage Patterning Task shown in Figure 16, they initially solved them in a disorganized manner, naming pairs of numbers that summed to 7 without searching for patterns both at the level of answers and organization. While the students managed to calculate possible pairs of answers, unfortunately, they felt rather unsure about whether they had generated all the possible answers. They eventually settled the issue when Marsha suggested the list shown in Figure 17. Over the course of several sessions, they solved similar problems involving different numbers (e.g., 52 mice, 147 mice). Later in the year when they revisited the problem, "the students remember(ed) the problem, easily generate(d) the possibilities, and predict(ed) how many possibilities there would be for any given number of mice" (p. 69).

Schweitzer's (2006) interesting account of her longitudinal research in her combined first and second-grade class also highlights the value of relational thinking in her students' developing understanding of numbers and operations. Throughout the two years of working with the same group of children, she emphasized a patterns approach to, or a structural way of, thinking about the commutative property of addition, addition and subtraction facts, and fundamental numerical propositions such as $a+b=c$ implies $a+(b+1)=c+1$ (e.g. if $6+6=12$, then what is $6+7=?)$ and $a+b=(a-x)+(b+x)($ e.g. $39+14=(39+10)+(14-10)=49+4=53)$, which made the resulting expressions easier and more reasonable to calculate than the original expressions. She also noted how models such as cubes and coupons (in the case of money) became tools that her students used to explain their reasoning and understanding.

Moss and London McNab's (2011) study with 42 Grade 2 students in the US and Canada investigated how they generalized rules for constructed (and not presented) function tables that had non-sequential pairs of inputs and outputs. In such cases, the students learned to focus on "the 'across' or function rule, rather than on the 'down' pattern or 'what comes next' strategy' strategy identified as interfering with functional generalizations” (p. 282). Consequently, the form of their generalizations was more explicit than recursive and covariational (i.e. expressing a consistent relationship between input and output).

\section{COMPETENCE WITH SHAPES AND SIMILAR RELATIONSHIPS}

Shape is not an inherent but an abstract property of any object, mathematical or physical (Pizlo et al., 2010), which implies that recognizing a shape involves conceptually constructing it via processes of abduction and induction in a dynamic manner. Here we foreground the perceptually relative nature of construction in a phenomenological sense, that is, one that draws primarily on one's personal experience(s) with an object (cf. Hill \& Bennett, 2008). The emergence of shape, in other words, is relational and viewpoint dependent (ibid.). However, we also note how our (neural and psychological) perception of the shape of objects can change and be modified with [ongoing] experiences and support from the environment (Triadafillidis, 1995; Wallis \& Bülthoff, 1999).

Pattern-related issues surrounding shape basically deal with the concept of similarity and, especially, the fixed and steady role of similarity in an emerging shape organization relative to a pattern (i.e., in Duval's (1999) sense of perceptual apprehension; Gal \& Linchevski, 2010). Sequences of figural objects such as the growing squares pattern in Figure 18 are similar because they have the same shape but not the same size ${ }^{1}$. Furthermore, depending on the

${ }^{1}$ Mathematically, the pattern stages in Figure 18 represent dilations, that is, there is a fixed central point of projection. There is no research that deals with pattern stages that appear as a sequence of similitudes, that is, similar figures that involve both isometry 


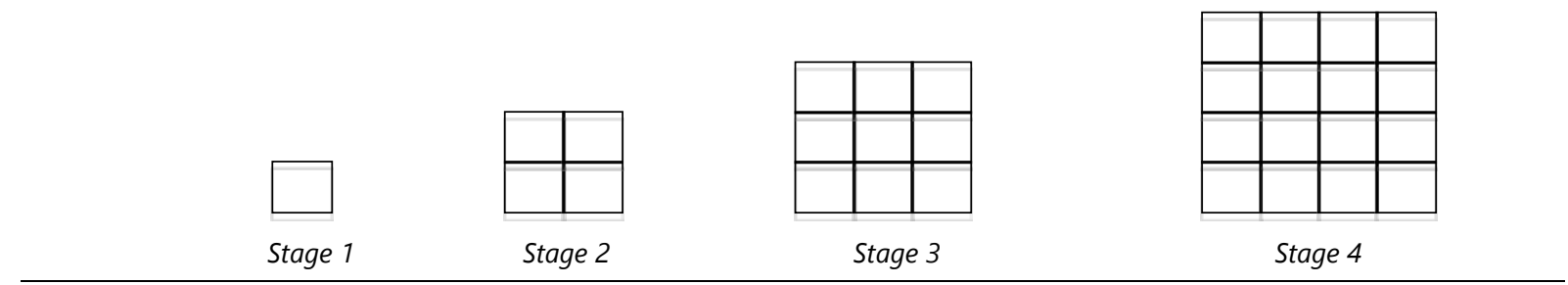

Figure 18. Growing Squares Pattern

Consider the pattern of unit squares below. How does stage 8 of the pattern appear to you? How many edges are there in all?

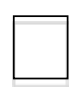

Stage 1

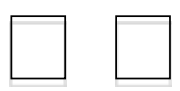

Stage 2

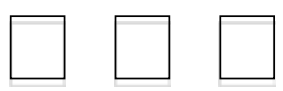

Stage 3
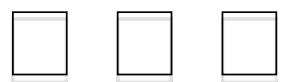

Stage 4

Figure 19. Separate Unit Squares Pattern

nature of the sequence or pattern conveyed through the stages, similarity means the relevant corresponding angles across the stages have the same measure and the corresponding parts are proportional according to some (constant) rule. Sequences of figural objects that all have the same size and shape are congruent. The separate unit squares pattern in Figure 19, which is a typical pattern in many lower elementary mathematics textbooks, consists of congruent unit squares with the stage number determining the number of congruent unit squares that are constructed. In the case of Figure 19, the uniform shape conveys that other attributes of the pattern are more relevant to pattern generalization than the figures themselves. When such patterns are given to first grade students, they often provide useful contexts for, say, skip counting activity and in introducing them to functions. In this subsection, we dwell on issues surrounding the more complex figural patterning tasks such as the one shown in Figure 18.

Basic object or shape recognition is a skill that is central to figural pattern generalization. What is oftentimes assessed in patterning activity is the consistency in which learners are able to conserve the same steady shape across the stages in a pattern. For example, the pattern stages in Figure $\mathbf{1 8}$ together convey the same shape of squares that have different dimensions. David's work in Figures 3, 6, and 8 preserved the same shape that he initially abduced on stages 1, 2, and 3 of the presented figural patterns. Among elementary school children in the lower grades, their usual introduction to figural pattern generalizing involves having them copy the same shape(s) over several cycles (i.e. repeating patterns). Such activities basically target object or shape recognition and the construction of similarity relationships.

But, how well do elementary students in the lower grades copy shapes of more complex figural objects? An interesting study by Mulligan, Prescott, and Mitchelmore (2003) conducted with 109 Year 1 Australian children (ages 5 to 7 years) assessed their ability to copy a given geometric shape. The children were briefly shown the triangle consisting of six circles in Figure 20. When then asked to draw what they saw on a separate sheet of paper, only about $20 \%$ of them produced the same triangle shown in Figure 20. Figure 21 shows several different responses that the authors categorized according to type of structure, that is, from having no structure to fully structural.

Certainly, Mulligan, Prescott, and Mitchelmore's (2003) findings can be interpreted in different ways. To begin with, copying a figural object requires the use of working memory. Just like the situation involving simple counting among young students, producing an exact copy (or count) means that they need to remember which aspect(s) of the figure (or items) have already been drawn (or counted). Feigenson (2011) notes that existing research findings claim that working memory is constrained by the "amount of information it can maintain at any given time" (p. 13) - that is, "observers of all ages appear able to concurrently represent three or four visual items in working memory but no more" (ibid, pp. 13-14; cf.: Alvarez \& Cavanagh, 2004; Feigenson \& Carey, 2003; Luck \& Vogel, 1997). Of course, the stipulated limit of 3-4 items could refer to 3-4 individual objects, sets of objects, and ensembles of objects.

and dilation. The squares in Figure 19 represent congruent figures that, by definition, can be established by applying at least one isometric action (Kay, 2001). 


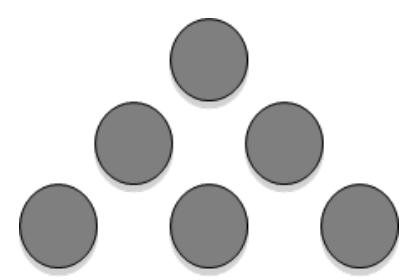

Figure 20. Triangle Task (Mulligan, Prescott, \& Mitchelmore, 2003, p. 24)

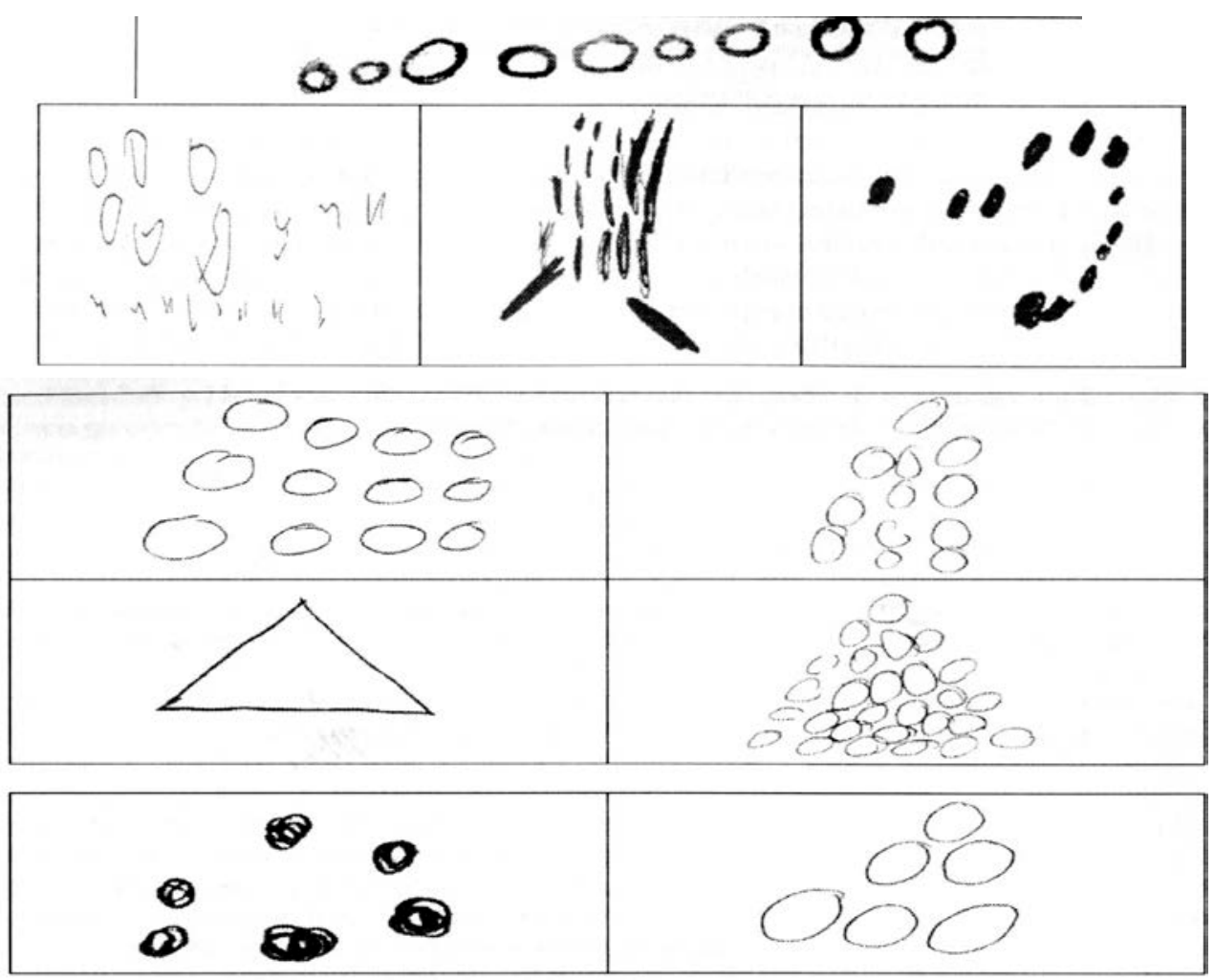

Figure 21. Samples of Year 1 Students' Work on the Figure 20 Triangle Task (Mulligan, Prescott, \& Mitchelmore, 2003, pp. 2526)

Cavanagh and He's (2011) work on spatial attentional mechanisms involving explicit counting of objects in static pictures and dynamic displays might also explain the different constructed figures shown in Figure 21. The remaining $80 \%$ of the students in Mulligan, Prescott, and Mitchelmore's study appear to have overcounted with a significant fraction of them unable to preserve the shape of the original figure. Cavanagh and He (2011) note that explicit counting in both static and dynamic displays necessitate the performance of at least four tasks, as follows: "select[ing] an uncounted item; increment[ing] the count; mark[ing] the just counted item; and stop[ping] when there are no more uncounted items (pp. 23-24).

In the case of static pictures of figural objects such as the triangle shown in Figure 20, we add the task of forming the objects in some stipulated arrangement. Based on their experiment with a small number of adult participants, Cavanagh and He (2011) note that the view in which "attention cannot count - at least cannot count to more than four [objects]" (p. 24) does not appear to hold, which leads them to conclude that no such upper limit exists. Our concern in their study involves their claim that "attentional system is capable of indexing individual objects in visual space" (p. 30), including their view that items arranged "in a way that minimizes overcrowding" enable individuals to engage in attentional indexing with a larger number of items. Hence, among elementary students, psychological issues such as constraints in working memory and their developing spatial and attentional indexing mechanisms might influence the manner in which they deal with more complex figural object representing and pattern generalizing such as the ones shown in Figures 18 and 20.

In light of the preceding discussion on possible psychological constraints in recognizing shapes, including the representational modes that are employed to describe their parts (e.g., qualitative verbal descriptions or quantitative count of objects; continuous and approximate or discrete and exact diagrams), Rivera (2010) assessed a group of US second-grade students' competence in extending several different kinds of increasing patterns prior 
2-Stage Ambiguous Task: Let us begin with a square and call it step 1. Now suppose step 2 looks like as shown. How many squares do you see?

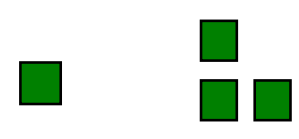

Step $1 \quad$ Step 2

A. How might step 3 appear to you? Show me with the blocks.

B. Show me steps 4 and 5. How many squares do you see?

C. Pretend we do not have any more blocks and suppose we skip steps. If someone asks you how step 10 looks like, how might you respond? Can you describe or draw it for me?

(In the second interview, we added step 3 as shown on the right. Students then constructed steps 4, 5, 8, and 10.)

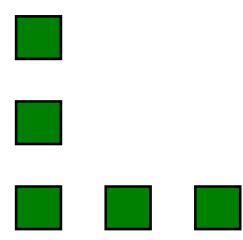

Step 3

Figure 22. A Semi-Free (Ambiguous) Pattern

House Pattern: These are how our stages in a pattern look like.

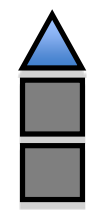

Stage 1

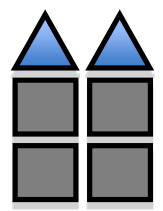

Stage 2

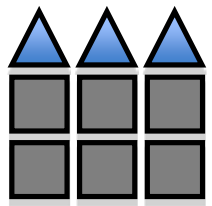

Stage 3

A. Can you show with the blocks what comes next? How might stage 4 might look like to you? How about stage 5 ?

B. Let us skip stages. Can you draw or describe in words how stage 10 might look like? How do you know for sure?

Figure 23. House Pattern Task

Flower Pattern: Below are the stages in our pattern.

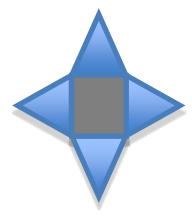

Stage 1

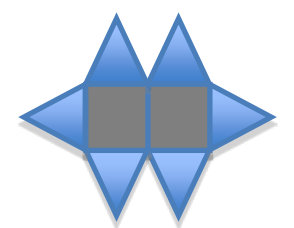

Stage 2

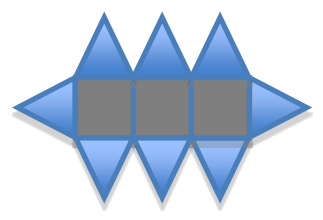

Stage 3

A. Can you show with the blocks what comes next? How stage 4 might look like to you? How about stage 5?

B. Let us skip stages. Can you draw or describe in words how stage 10 might look like? How do you know for sure?

Figure 24. Flower Pattern Task

to any formal intervention. We note that the students involved in this particular study were the same ones that we talked about in the preceding section on numbers. All in all, the students participated in a series of three clinical interviews each. In the first interview, they dealt with the two-stage semi-free (ambiguous) patterning task shown in Figure 22 in addition to the numerical patterns. In the second interview, a slight modification of the same ambiguous figural task was presented with three instead of two initial pattern stages. In the third interview, they dealt with the three 3-stage figural patterns shown in Figures 23, 24, and 25, which appeared to be more welldefined and possessed greater causal potency than the pattern in Figure 22. 
Triangle Pattern: Let us form a pattern from circles. Stage 1 has one circle. Let me build stage 2. How many circles are there? Let me build stage 3. How many circles are there this time?

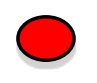

Stage 1

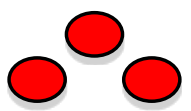

Stage 2

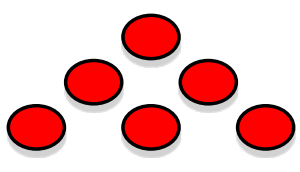

Stage 3

A. Can you show with the circle chips how stage 4 might look like to you? How about stage 5?

B. Let us skip stages. Can you draw or describe in words how stage 10 might look like? How do you know for sure?

Figure 25. Growing Triangle Pattern Task

In this section, our discussion focuses on the shapes of their extensional (or far) generalizations that we basically assessed on type of similarity alone. That is, similarity performance in figural pattern generalization ranges in competence from having no similarity across the pattern stages to manifestations of partial similarity and then to evidence of full similarity. A figural pattern that is fully similar to a learner means that there is an interpreted consistent (steady) shape that is conserved and shared across the given stages and the constructed extensions of the pattern. A figural pattern that is partially similar means that there is at least one notable local inconsistency in any of the constructed shapes despite the manifestation of a common or shared shape across the stages of the pattern. Sources of inconsistency pertain to those factors that distort the abduced similarity relationships (e.g. careless attention paid to the relevant angles, drawn stages that have disproportionate features of the same shape). A figural pattern that has no similarity implies that there is no common, similar, and steady shape that binds and organizes any of the pattern stages together in some way. In developing the categories for types of similarity, we acknowledge the possible interactions of other factors such as the continuous and approximate versus discrete and exact senses in which young learners perceive objects and their shapes. Such interactions have been carefully monitored in both data collection and analysis phases of the study.

Table 5 provides summaries of the students' responses in relation to the semi-free task shown in Figure 22. Over the course of two interviews, about $80 \%$ of the students did not construct any meaningful similarity relationship across the given stages of the pattern. Increasing the known stages from two to three also did not help. Consequently, none of them managed to produce an incipient generalization. Figure $\mathbf{2 6}$ shows common extensions that are not similar. The students who constructed them simply added one circle to three circles and did not provide an explanation. Some students like Skype narrowly focused on stage 3. They counted 5 circles altogether and then constructed extensions that had 2 circles more than the stipulated stage number that, in fact, became the rule for their emerging pattern. Some other students like Katya initially recognized the sequence 1, 3, and 5, saw that the values increased by 2 , and then simply used the blocks on the table to help them obtain the succeeding values without paying any attention to shape at all. 
Table 5. Grade 2 Students' Pattern Generalization Involving the Semi-Free Task Shown in Figure 22

Given:

Given:

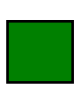

\begin{tabular}{c}
\hline \\
\hline \\
\hline FS \\
\hline 1 \\
\hline 1 \\
\hline 1 \\
\hline 0 \\
\hline
\end{tabular}

\begin{tabular}{lccc}
\hline & NS & PS & FS \\
\hline Near Stage 3 & 18 & 2 & 1 \\
\hline Near Stage 4 & 18 & 2 & 1 \\
\hline Near Stage 5 & 16 & 2 & 1 \\
\hline Far Stage 10 & 2 & 0 & 0 \\
\hline
\end{tabular}

\begin{tabular}{cccc}
\hline & NS & PS & FS \\
\hline Near Stage 4 & 16 & 2 & 0 \\
\hline Near Stage 5 & 16 & 2 & 0 \\
\hline Near Stage 8 & 14 & 2 & 0 \\
\hline Far Stage 10 & 2 & 0 & 0 \\
\hline
\end{tabular}
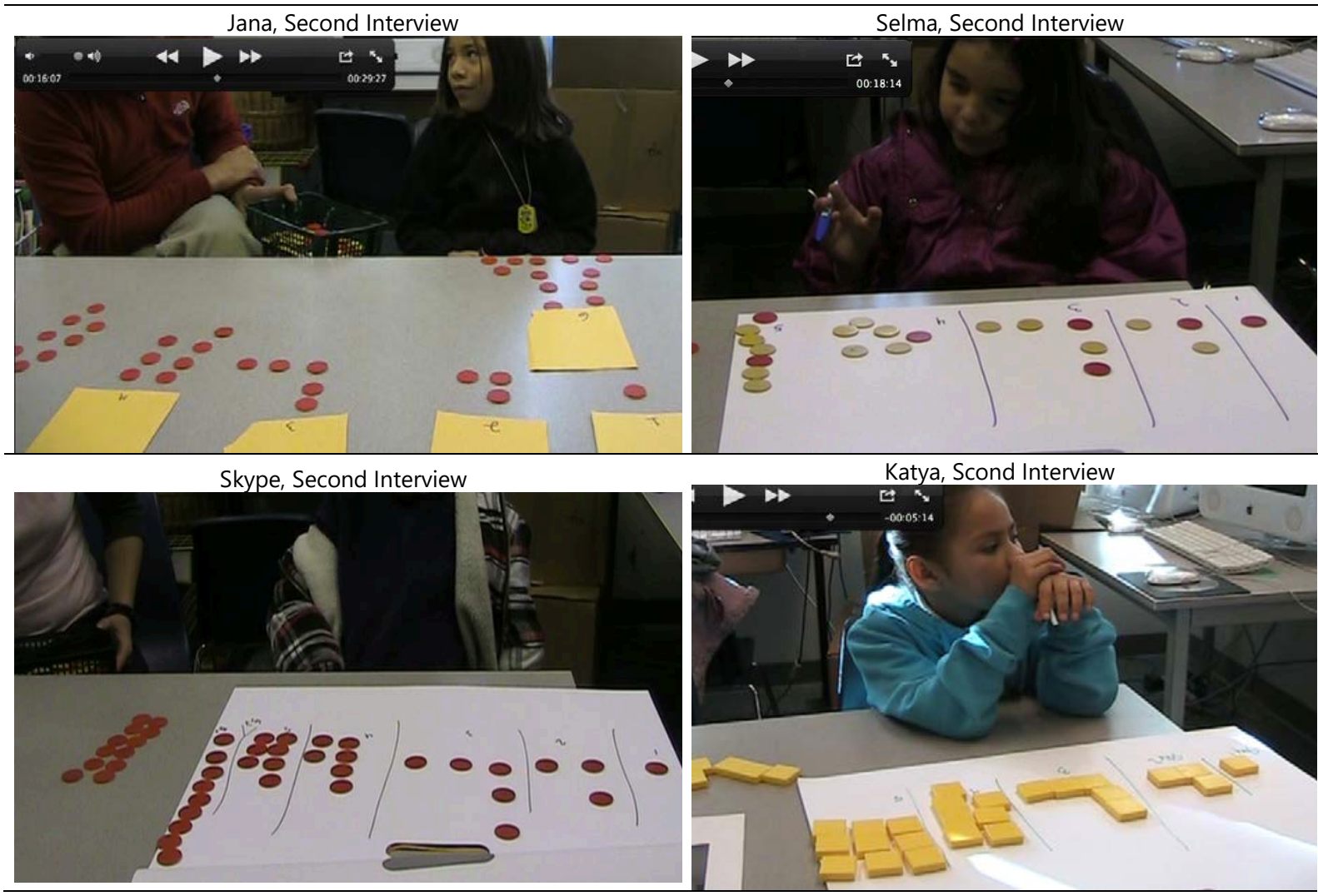

Figure 26. Examples of No Similarity Extensions of the Figure 22 Semi-Free Pattern

Figure 27 shows two students' work that exhibited partial similarity. Lina abduced the same L-shaped figure across her pattern but was inconsistent in terms of the dimensions of the two legs. Gemiliano also abduced the same L-shaped figure and produced the following sequence: $\{1,2+1,3+2,4+1,5+2,6+1,7+2,8+1\}$. Each stage in his pattern consisted of two columns of circles with the first column of circles corresponding to the stage number and the second column oscillating between 1 and 2 circles. Unfortunately, he was unable to deal with stage 10 solely on the basis of his abduction. Further, he could not explain the role of stage 1 in his pattern. 


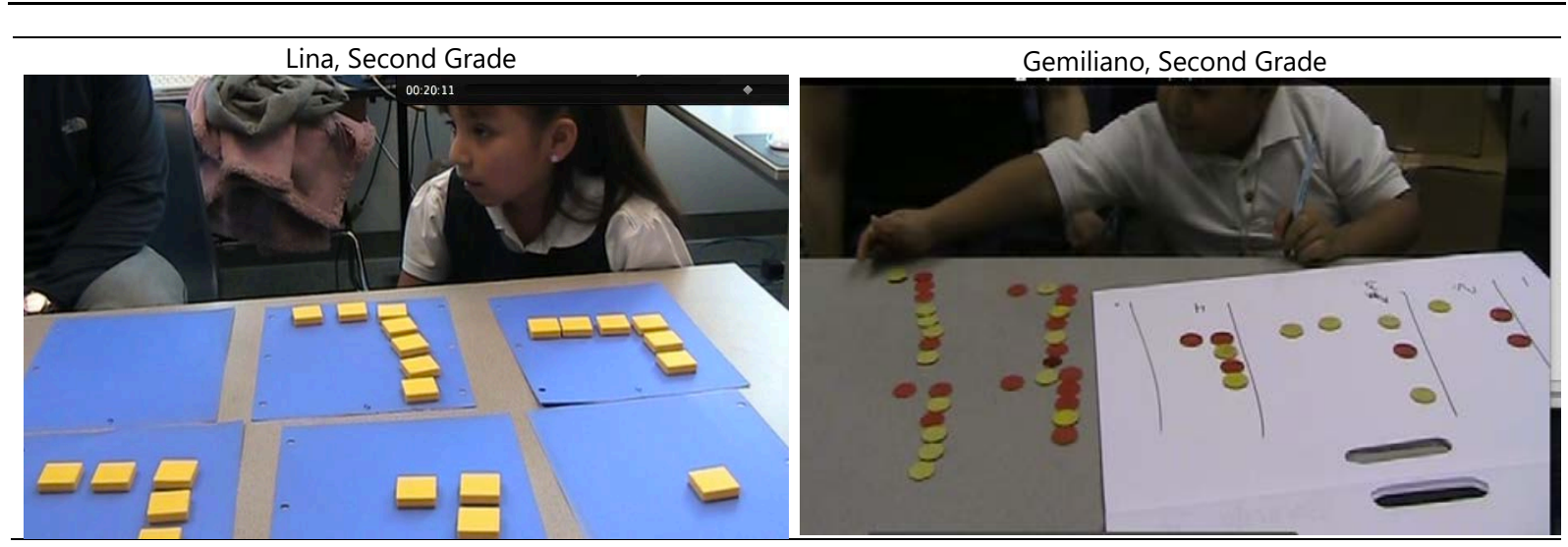

Figure 27. Examples of Partial Similarity Extensions of the Figure 22 Semi-Free Pattern

Table 6. Summary of Grade 2 Students' Responses on Figures 23-25 Figural Patterns $(n=20)$

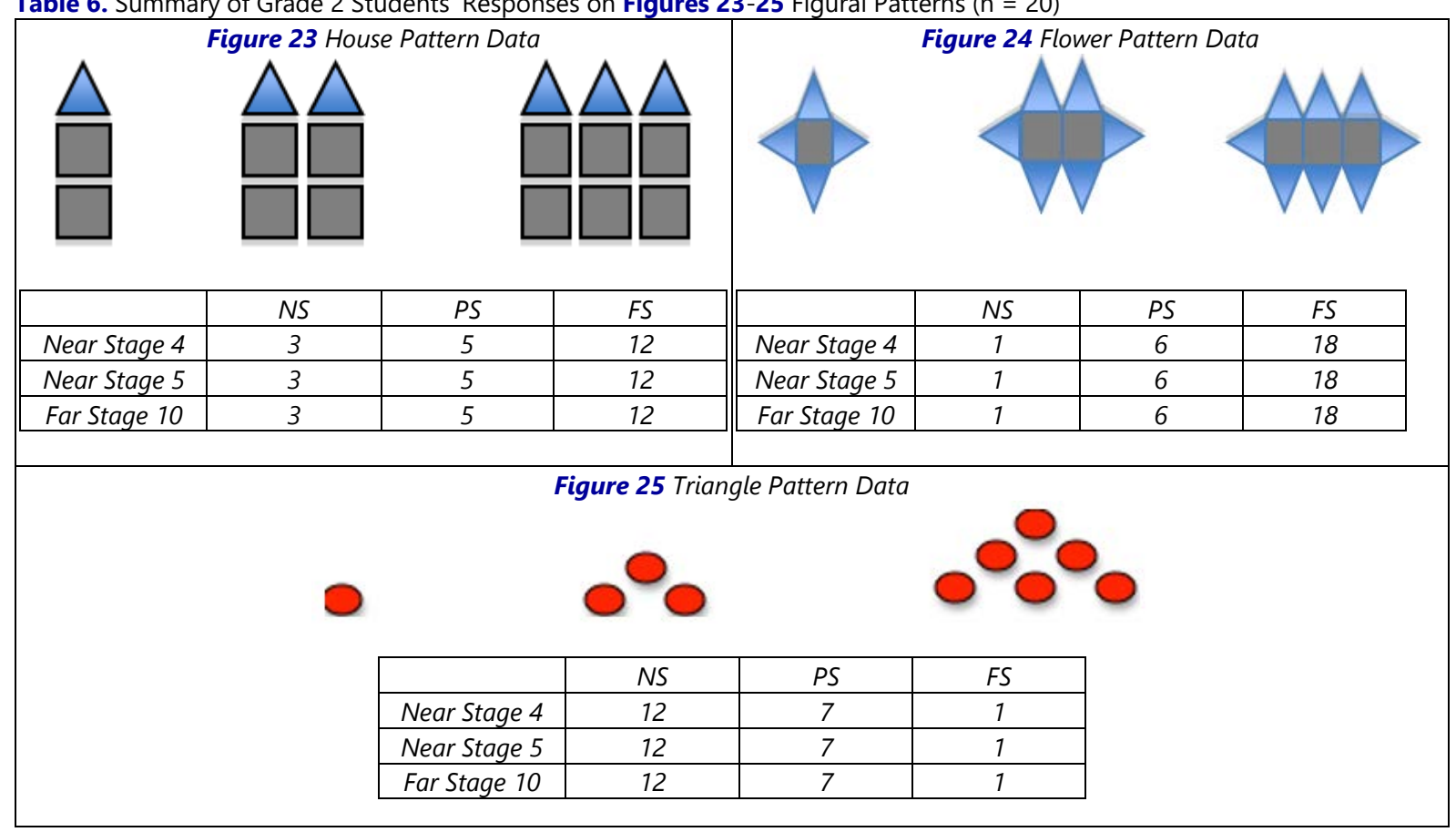

Table 6 provides summaries of the students' responses for the figural patterns shown in Figures 23, 24, and 25. The Flower Pattern task in Figure 24 produced more fully similar figures than the House Pattern task in Figure 23, while the Triangle Pattern task in Figure 25 produced fewer fully and partially similar figures than either the Flower Pattern or the House Pattern task. Except for one student who consistently produced fully similar figures. In all three tasks, each remaining student's overall performance during the same interview session exemplifies how similarity performance as it relates to pattern generalization is influenced by the nature and complexity of the task under consideration. Figures $\mathbf{2 8}$ and $\mathbf{2 9}$ show samples of underdeveloped or unsteady similar figures on the Flower Pattern and the House Pattern tasks. Among the partial similar responses in Figure 28, the most significant difficulty was how to account for the appropriate number of triangles that surround the middle squares. Some students either overcounted (Eddie and Jana) or undercounted (Jake). In Juan's case, when he was asked if he saw anything that was interesting to him within and across the given stages, he claimed that he saw triangles and squares and nothing else. In the case of the House Pattern, Jana in Figure 29 also thought like Juan in Figure 28, while those students who produced partially similar figures once again either overcounted (Lina in Figure 29) or undercounted (Gemiliano in Figure 29) the number of squares under each triangle. 

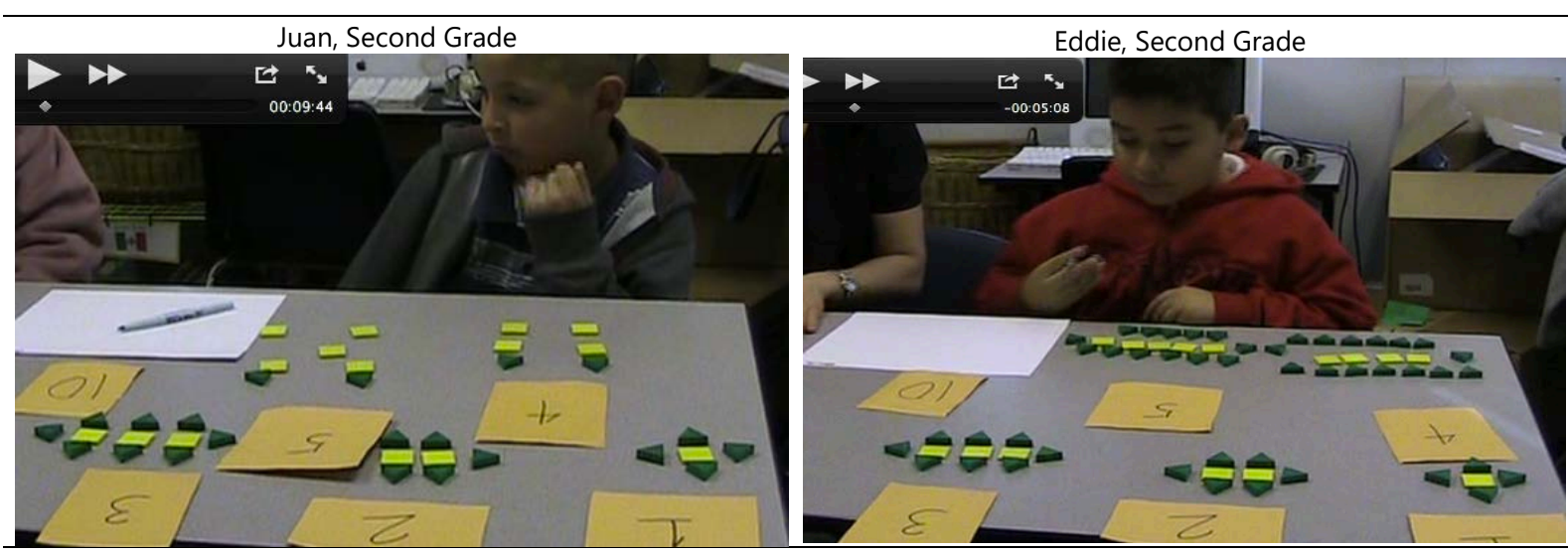

Jana, Second Grade
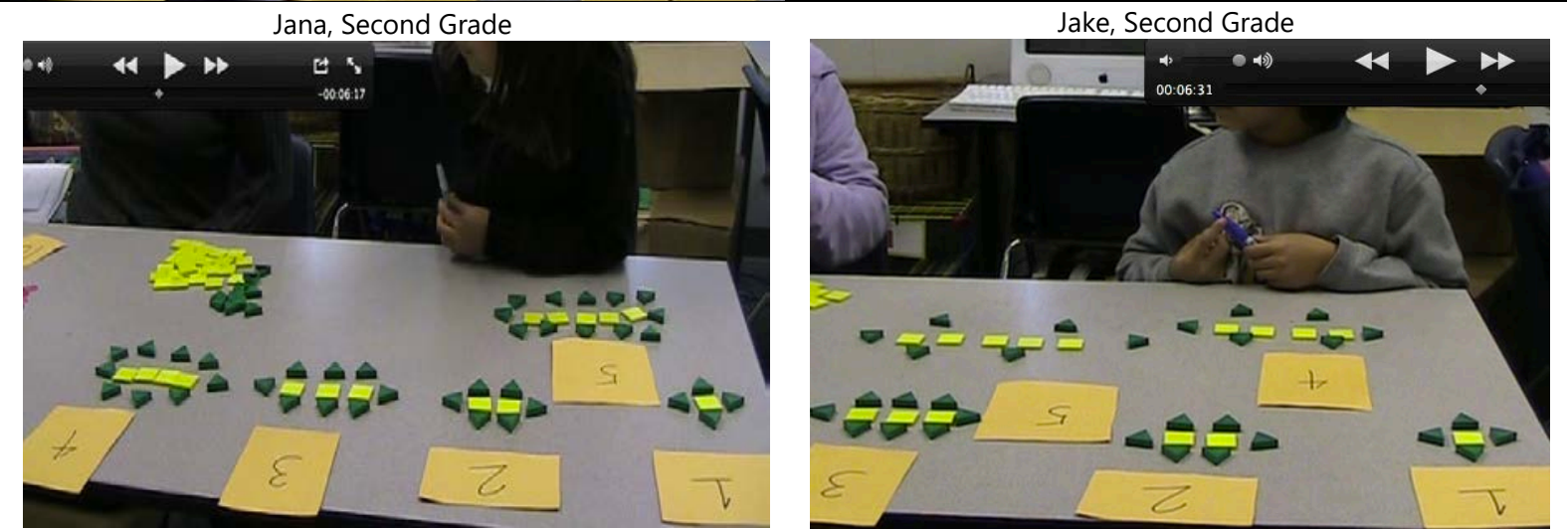

Figure 28. Samples of Underdeveloped Similar Figs. for the Flower Pattern in Figure 24
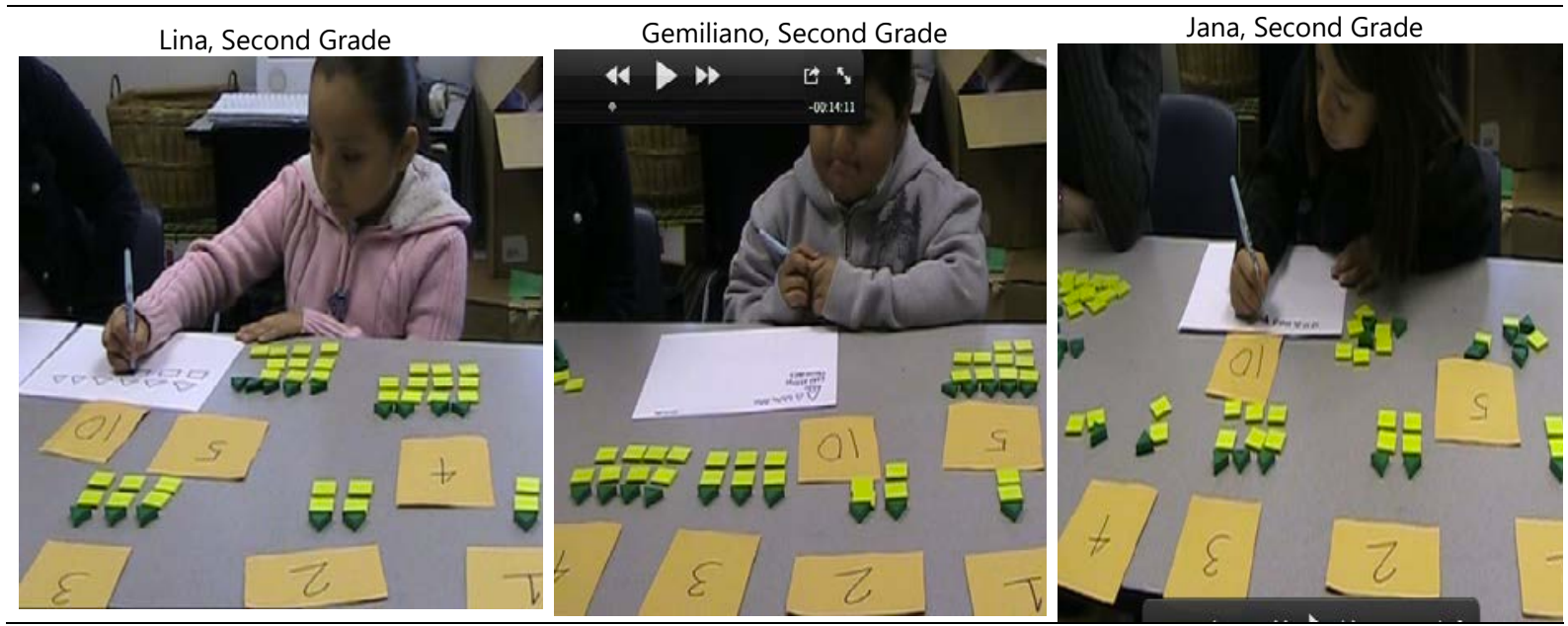

Figure 29. Partially Similar Responses on the House Pattern in Figure 23

The Triangle Pattern in Figure 25 was an ambiguous task for most of the students. While the intent was not to suggest or impose a growing triangle that only one student inferred on the pattern (Joko in Figure 30, about $60 \%$ of the students produced different figures from stage to stage (Cesar, Lina, and Eddie in Figure 30), thus, indicating no similarity in their perceptions of the pattern stages. Among the no similar responses, a few of them justified their figures by appealing to the successor property of whole numbers (Cesar: "stage 3 has 6 circles, so stage 4 has 7 circles, stage 8 has 8 circles"), while a few others abduced that the number of circles at any given stage would be twice the stipulated stage number (Lina: "stage 3 has 6 circles, so stage 4 has 8 circles, and stage 5 has 10 circles"). But there were more students like Eddie than Cesar and Lina who simply added circles from stage to stage to indicate that they were seeing an increasing pattern and nothing else. Among those who produced partially similar figures, either they overcounted (David), or narrowly focused on one aspect of their Figs. (Alain), or narrowly specialized on a given stage (Drake). 

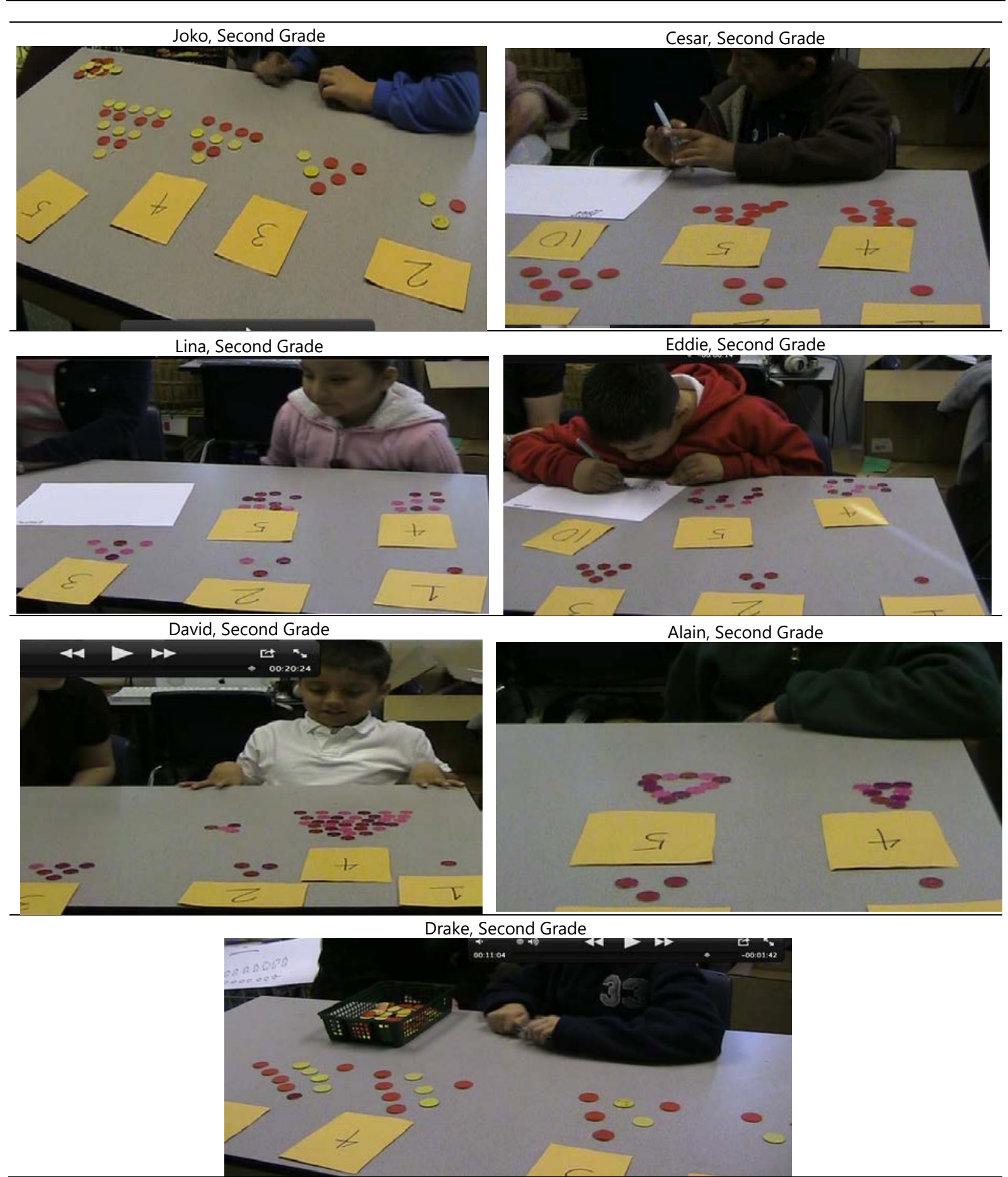

Figure 30. Student Responses on the Triangle Pattern in Figure 25

\section{COMPETENCE WITH FIGURAL PROPERTY DISCERNMENT, CONSTRUCTION, AND JUSTIFICATION}

While shape similarity in the preceding section is a perceptual apprehension phenomenon, figural property discernment requires operative apprehension (Duval, 1999). An operative apprehension of an object involves an interpretive generation and construction of properties involving units, parts, features, components, or configurations that characterize and organize an emerging structure relative to the perceived object. It is both innate and learned depending on factors that influence its emergence. In (exact) patterning activity, the primary issue 
involves the extent to which individual learners are capable of discerning properties that produce structures of a particular kind.

Elementary school children with no formal experiences in patterning are likely to establish properties that rely on similarity obtained through (surface) appearances. With more formal training, however, they will learn to perceive such properties in terms of (function) rules that emerge as a result of coordinating their inferential processes of abduction, induction, and deductive closure. For example, David in Figure 2 initially abduced houses consisting of triangles and squares that increased by the stage number. He then induced his structure on his fourth and the fifth step (Figure 3). His drawn stage 10 in Figure 4 could be interpreted as a consequence of implementing a deductive argument, which involves using both his abduction (general rule) and the available instances on the table (the stages) as his hypotheses that enabled him to necessarily conclude that stage 10 would have the same structure of triangles and squares. Hence, a mathematically valid figural property discernment in pattern generalization activity involves the construction (abduction and induction) and justification (deduction) of rules that apply within and across the pattern stages. In Duval's (1998) terms, the construction phase recruits both perceptual and operative apprehension mechanisms, while the justification phase employs discursive apprehension in which case the necessary figural properties that apply to the stages in a pattern are causally explained relative to an interpreted structure that produced them in the first place. Discursive reasoning from near to far generalization consequently shifts in context from describing the necessary steps (i.e., properties) in constructing the known stages in the pattern to being entirely independent of the operative dimension, where the structure is necessarily imposed (i.e., structurally argued) on the projected far stages of the pattern.

However, the emergence of such rules among elementary school children is fraught with a few conceptual difficulties. Especially in the case of growing patterns, first-grade students' initial patterning experiences oftentimes involve establishing recursively additive generalizations (Blanton \& Kaput, 2004; Taylor-Cox, 2003). For example, a rule for the pattern in Figure 19 would have them constructing the rule "add 4 sticks at each stage to form a new square," which is not an algebraically useful generalization. Thus, pattern generalizing would need to take into account the possibility that such prior knowledge is likely going to manifest itself in their emerging generalizations. The dilemma, of course, is that discerning the property of adding 4 each time to generate a new square from one stage to the next does not appear to be as essential as perceiving the pattern in terms of sides that increase by multiples of 4 , which is an algebraically useful generalization. When an emergent generalization has the property of algebraic usefulness, any far generalization task could then be induced without having to construct the preceding stages, which is a rather inefficient strategy that is performed in any case of recursively additive generalizations. The figure on the right of Figure 31 shows a US third-grade student's long process for generating the total number of squares in stage 10 in relation to the figural pattern on the left. Nikki initially saw that the pattern was increasing by 2 squares at every stage. She then constructed stages 4 and 5 with circle counters following her recursive rule. In dealing with stage 10, she transitioned numerically from the figural cues and patiently added 2 until she obtained 23 squares total. Tanisli and Özdas (2009) also report similar findings concerning the prevalent use of recursive formulas among Grade 5 students (mean age of 10 years) in Turkey when they established generalizations for linear and quadratic figural patterns.

Hence, figural property discernment involves the construction and justification of algebraically useful configurations. Following Duval (1999), such discernment fundamentally involves cognitive actions of processing and conversion beyond mere visual perception ${ }^{2}$, where processing involves implementing figural operations such as making figural transformations or reconfigurations on the pattern stages in order to see an emerging structure better and conversion involves translating one representational context into another (e.g., Nikki's combined verbal and pictorial description that transitioned to numerical sentences in Figure 31). Figure 32 exemplifies figural processing strategies that have been drawn from the work of three Australian Year 5 students (ages 9 to 10 years) in Cooper and Warren's (2011) study who processed the stages in the given pattern using different but equivalent ways. Their converted representations reflect the processing they imposed on the stages. All three of them operatively apprehended growing twin towers of blocks. Ron saw one tower with height $(n+1)$ and another tower with height $n$. For Sue, the tower consisted of two equal columns of blocks with an extra block on the top left column. Jane initially imagined a full two-column tower of blocks that enabled her to calculate its height, $2 \times(n+$ 1). She then subtracted 1 from the total height in order to convey that she was taking away the unnecessary block that was initially added.

${ }^{2}$ For Duval (1999), visualization is an "intrinsically semiotic" (i.e., neither mental nor physical) cognitive activity. He distinguishes between visual perception (vision), which is primitive, and visualization, which has both epistemological and synoptic functions. Vision primarily engenders direct access and intuition of objects, while visualization involves the construction of a (semiotic) representation (epistemological function). In any semiotic representation, "relations or, better, organization of relations between representational units" are noted, including and especially those that are not at "all that accessible to vision" (Duval, 1999, p. 13). Also, while vision initially apprehends objects and their totality, it is never a "complete apprehension" (ibid.) unlike visualization that engenders discourse and deductive actions such as acts of focusing and noticing (synoptic function). 


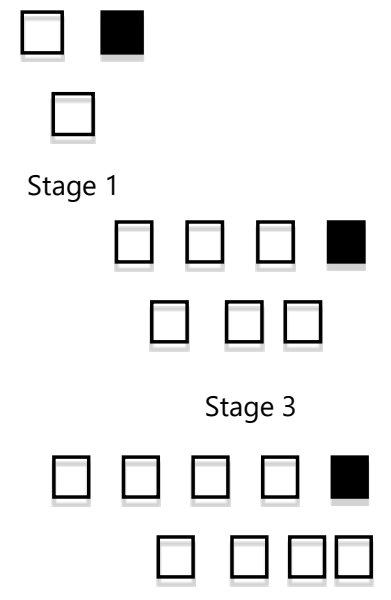

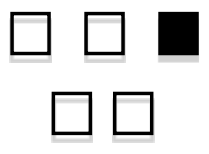

Stage 2

Stage 4

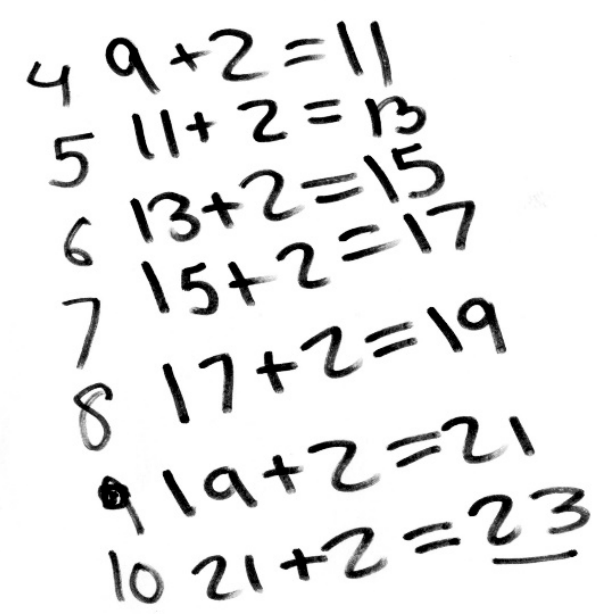

Figure 31. US Third Grade Student's Pattern Generalization of the Two-Row Patterning Task

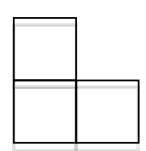

Step 1

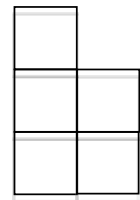

Step 2

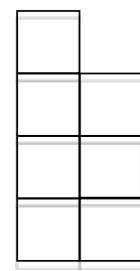

Step 3

Ron Sue Jane

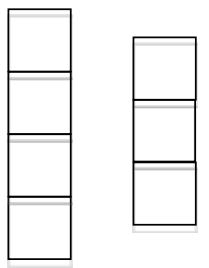

$(\mathrm{n}+1)+\mathrm{n}$

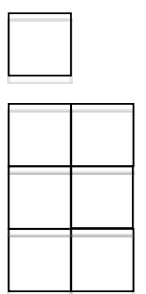

$2 \times n+1$

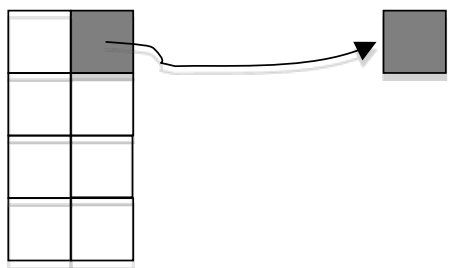

$2 \times(n+1)-1$

Figure 32. Year 5 Students' Algebraically Useful Structures for the Tower Pattern (Cooper and Warren, 2011, p. 198)

What is apparently complex among learners when both cognitive actions of processing and conversion are performed deals with matters that pertain to their coordination, especially "between the registers of representation" in the conversion phase (Duval, 1999, p. 11). Of specific concern to figural processing of patterns deals with what Lee (1996) refers to as perceptual agility, which pertains to the acquired ability of "seeing several patterns and a willingness to abandon those that do not prove algebraically useful" (p.95). If a figural processing is not likely to yield an algebraically useful conversion, the task of changing in register from, say, the verbal to the algebraic is expected to be a difficult and an almost impossible undertaking. Nikki in Figure 31, for example, figurally processed a nonalgebaically useful recursive structure that she verbally described in clear terms. However, she was unable to apply it when she had to deal with stage 100 of the pattern. Duval (1999) notes that learners need to learn how to select the relevant configurations that "could cause the anticipation of the kind of" (p. 17) meaningful conversions that are congruent, an "essential condition" that brings forth a sufficient "transparency" and, thus, enables an "easy translation" from the "starting register to the target register" (ibid, p. 10). For figural patterns, like geometrical objects, "have not one but many possible configurations or subconfigurations" (ibid, p. 17).

Since (exact) figural processing that yields algebraically useful structures appears to be necessary, its emergence and development effectively take place in socially objectifying situations and activities. The term socially objectifying is used in Radford's (2010) sense in which students in joint activity with one another "become acquainted with historically constituted cultural meanings and forms of reasoning and action" (p. 3). 
For example, a classroom mathematical activity is seen as the site of a relational-driven communal zone of proximal development, where "instruction leads the course of development and that such a course depends on the kind of relationship that is created between [a] student and her context" (ibid). Radford (2010) illustrates a socially objectifying figural processing in the context of his work with a class of Grade 2 Canadian students (ages 7 to 8 years). When the students began to investigate the pattern on the left in Figure 31, one group of students initially abduced the common difference of 2 squares between two consecutive dependent terms and appeared oblivious to possible spatial configurations that could be interpreted from the pattern stages. Realizing this, the teacher, Natasha, stepped in and collaborated with them in constructing an algebraically useful structure that consists of a bottom row with $n$ squares and a top row with $(n+1)$ squares. In the joint activity phase, Teacher Natasha implicitly conveyed to the group an intentional abduction that then became their basis for further induction. Certainly the abductive structure became explicitly known to the group via pointing gestures, words, and rhythm, which could be considered as grade-level appropriate semiotic means of objectification. We should also note that in the reported classroom study, Teacher Natasha shared with the entire class another group-generated algebraically useful structure - that is, two equal rows of white squares and a dark square - that enabled the students to deal with two additional far generalization tasks.

In closing the patterning activity analysis with the students and their teacher, Radford (2010) points out that an (exact) figural conversion of the students' structures did not involve transformations in representational forms from the verbal to the algebraic consisting of variables, terms, and operations. Rather, their converted generalizations reflected the use of "embodied formulas" that "instead of being expressed through letters [are] expressed through actions unfolding in space and time" (p. 7).

A further analysis of Radford's (2010) study highlights the significant role of the teacher in the social objectification of exact figural processing, which involves coordinating shape, numerical count, and figural configurations around mathematical conditions of consistency and stability in pattern generalization (cf. Carraher, Martinez, \& Schliemann, 2008; Warren \& Cooper, 2007) For example, in a series of inductive actions with her students on the pattern shown in Figure 31, the teacher (Natasha) initially asked them to "look at the squares at the bottom ... just the squares at the bottom" (p. 4). She then engaged them in a series of verification steps, as follows: "In Term 1, how many?" “Term 2?" “Term 3?" “Term 5?" “Term 6?" “Term 7?" “Term 8?" She employed the same rhythmic pointing gestures for the top row squares.

Warren and Cooper (2007) also note the effective use of teacher-mediated figural parsing in the context of their patterning work with Australian Year 4 students (mean age of 9 years). They point out that their students began to perceive patterns in terms of having a structure with invariant parts as a consequence of the joint activity that took place between them and their teacher. We contrast this particular finding with inexact and approximate figural processing of patterns that many elementary students have been documented to manifest in some cases of patterning tasks in the absence of any formal instruction or intervention from their teachers. Some students, like David in Figure 7, Lina in Figure 27, and the children in Figure 28, could figurally process stages into parts. However, the parts themselves do not reflect a consistent and stable structure across the pattern stages. Some other students, like Gemiliano in Figure 27 and Drake in Figure 30, could also figurally process stages into parts. However, they tend to ignore the initial stages in a pattern and instead narrowly specialize on the last given stage of the pattern. Consequently, while their extended stages may appear to be consistent and stable, the stages altogether fail to be an unambiguous and a well-defined pattern.

(Exact) Figural processing that yields algebraically useful structures may also occur in objectifying situations and activities that are not fully social, that is, without assistance from, say, a teacher. This happens in cases of patterning tasks that either have figural goodness or are causally potent, which makes the task of figural processing easy to accomplish. In such cases of patterns, they possess an arrangement that has evident structural features such as symmetry and repetitiveness and could, thus, be figurally parsed without much effort (Pothos \& Ward, 2000; Rivera, 2011). For example, in Table 6, roughly 15 out of 20 second-graders in Rivera's (2010) study obtained correct far generalizations on the Figures 23 and 24 patterns in the absence of formal instruction. Their constructed near and far generalizations reflect a consistent and stable interpreted structure across the given and extended pattern stages. However, we underscore difficulties in (exact) figural conversion, in particular, in third grade (i.e. the following school year) when those same second grade students were asked to transform their verbally-based structures into an arithmetical expression involving both addition and multiplication operations ${ }^{3}$.

\footnotetext{
${ }^{3}$ Context of the clinical interviews in third grade: The interviews took place toward the end of the school year without any intervening teaching experiment on patterns. Lack of instructional time prevented the third-grade class from exploring patterning activity. However, the author worked with the third grade teacher in ensuring that the entire third grade mathematics curriculum fostered structural and multiplicative thinking within and across the strands (i.e. number sense, algebra, statistics, data analysis, and probability, and geometry and measurement). Like in the previous year, individual students were clinically interviewed on the five figural patterning tasks shown in Figure 33. In each task, they were asked to: (1) construct stages 4 and 5 based on their initial interpretation of the given stages; (2) verbally describe stage 10; (3) try to transform their verbal description in arithmetical
} 
Cross Pattern

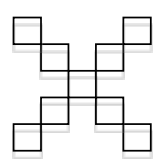

Flower Pattern

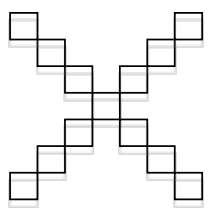

$\square$
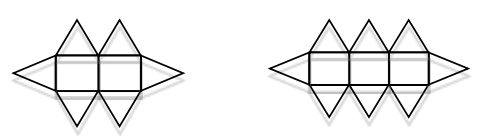

Two-Row Pattern
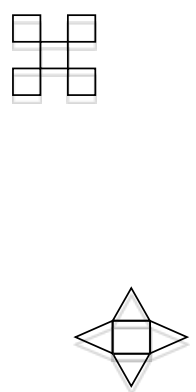

L-Shaped Pattern
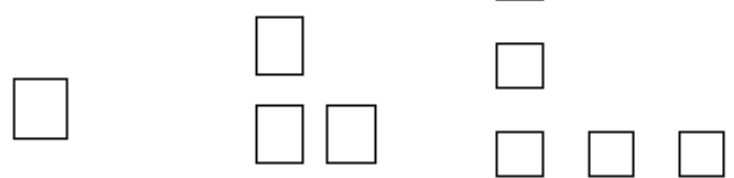

Semi-Free Task

Figure 33. Patterning Tasks for Third Graders

Table 7 provides a summary of the third grade students' pattern generalization performance on the five tasks shown in Figure 33. Less than 58\% of the 19 students interviewed were successful in transitioning from the specificity of their constructed stages and verbal-based structural descriptions to an arithmetical direct expression. Among those who were unable to perform a conversion, they experienced considerable difficulty in bringing together and coordinating two different registers of representations for the same object (i.e. patterns) resulting in a conversion split. Among those who were successful in converting, however, both their verbally induced structures and arithmetical expressions were congruent.

form involving whole numbers and the operations of multiplication and addition; and (4) state the total number of objects in stage 100 by using the arithmetical formula they established in (3). Concrete blocks were provided throughout the interview. Drawn pictures of the pattern stages were shown one by one. The students then had the option of using the blocks to reconstruct the stages, however, we asked them to draw all the extended stages on paper. 
Table 7. Third Grade Students' Performance on the Pattern Generalization Tasks Shown in Figure $33(n=19)$

NStage 4 NStage 5 FStage 10 Far Generalization Expressions

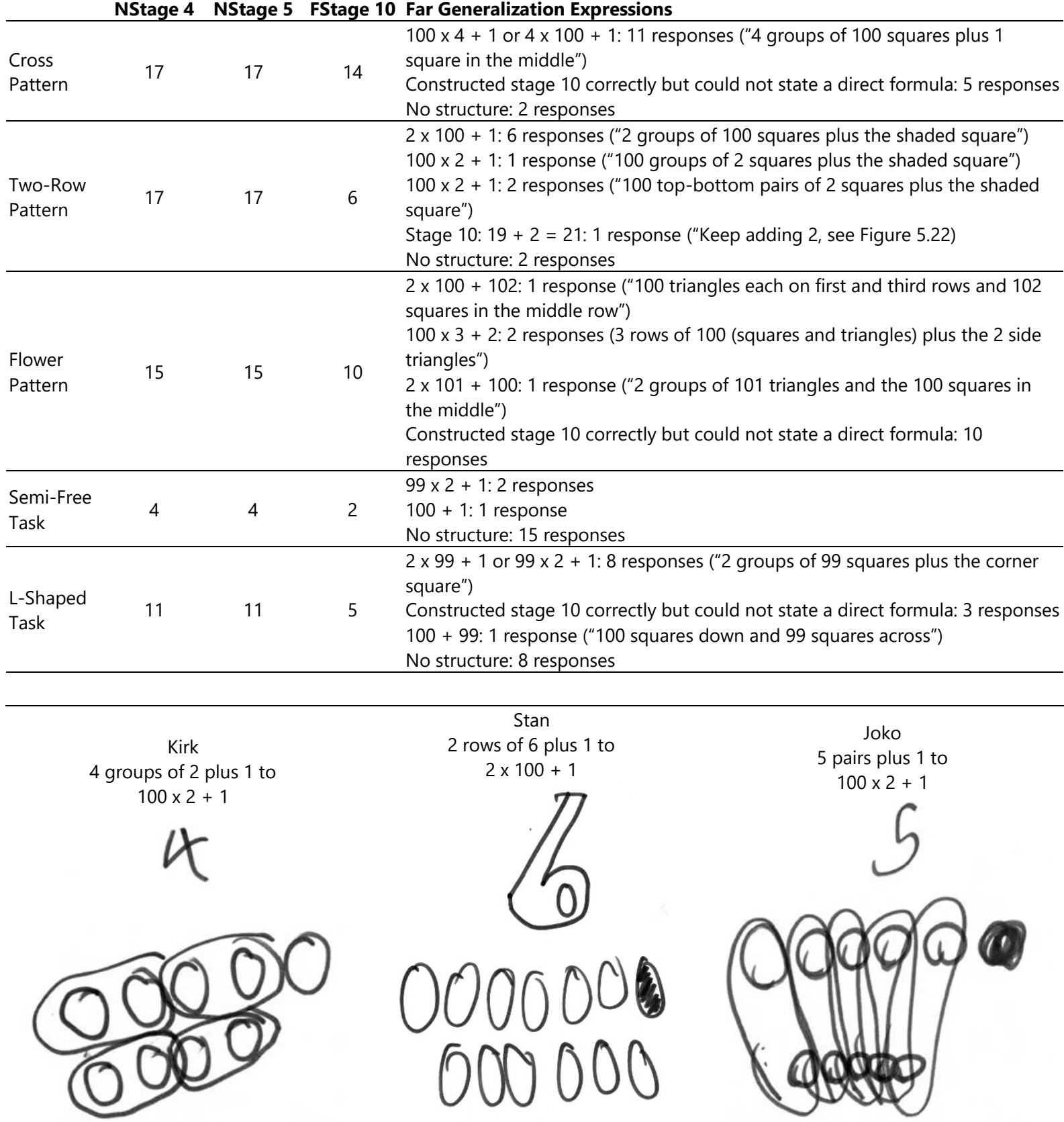

Figure 34. Three Different Structures for the Two-Row Patterning Task in Figure 33

Figure 34 illustrates three different algebraically useful structures for the Two-Row patterning task in Figure 33. In all three cases, the students successfully coordinated their figural processing and conversion in a single action. Stan's generalization was the most frequent response. He immediately saw "two rows of circles and a dark circle" that he then conveyed arithmetically in that order, "[stage 100\} there are two rows of 100 circles, 2 x 100, plus 1 for the [dark] circle at the end." The responses of Kirk and Joko reflect the manner in which they understood the concept of multiplication of whole numbers, which explains the evident use of circling groups of two objects that led them to their respective generalizations. 


\section{IMPLICATIONS FOR MATHEMATICS LEARNING: ELEMENTARY STUDENTS' EMBODIED GENERALIZATIONS ON PATTERN GENERALIZATION TASKS RANGE IN TYPE, FORM, AND CONTENT}

Based on the foregoing discussion, elementary students are naturally drawn to expressing their incipient generalizations in several different ways, and their competence depends, at the very least, on the nature and level of complexity of the patterning task that is presented to them. What is amazing regarding children who have not been exposed to formal experiences in patterning is their disposition to choose representations that they consider meaningful, which conveys the embodied nature of their generalizations that are all directly tied to their perceptual apprehensions, operative assumptions and expectations, and sensorimotor actions with the patterns. Hence, their representations take shape in many forms through the use of gestures, pictures, words, numbers, and combinations of forms depending on their prior and ongoing experiences and context. Also, while their constructed expressions of generality oftentimes involve pictures, words, and numbers, their justifications tend to be primarily gestural in nature at least prior to formal instruction. For example, David in Figure $\mathbf{2}$ employed the same steady gesture as a way of expressing how he was apprehending the general shape of the given pattern stages.

One consequence of formal instruction in patterning involves gesture fading in which case gestures are converted to diagrams in the form of external grouping processes such as the circling method in Figure 34 . The diagrams then become the basis for converting to, and explaining, the corresponding arithmetical expressions. Suffice it to say, the quality and content of elementary students' pattern generalizations over time could be explained by their reliance in using their actual (physical) actions with patterns and the learned context in which they begin to abduce (conceptual) relations that they extract from their actions.

While Radford (2010) in the preceding section has referred to elementary students' generalizations in patterning activity as exemplifying instances of embodied formulas, they, in fact, produce at least three different kinds of abductively-driven generalization, namely, structurally iconic, indexical, and symbolic generalizations (Rivera, 2011). In the initial phase, their structurally iconic and indexical direct expressions resemble quite faithfully the structural contexts of their emergence - that is, their meanings are linked to how they are apprehended both perceptually and operatively by individual learners. The numerical terms convey how many objects are seen (a perceived similarity between sign and object, hence, iconic), while the overall verbal, gestural, and/or arithmetical expression with either the indicated or implicitly stated operations show how the objects are concretely and physically seen (an inferred relationship between sign and object, hence, indexical). Later, during the deductive closure phase of generalizing, where both the rule (established by abduction and induction) and the known instances (both given and extended stages) are used as hypotheses to justify a conclusion (an inferred structure for the projected stages), the expressions further evolve into structurally symbolic generalizations. At this point, the focus of cognitive attention is the rule itself. When this situation occurs, students conceptually disregard the objects that comprise the stages in favor of the rule, which is determined by some (learned or social) convention, rule, code, agreement, or causality. For example, the circling process and the use of the term " $m$ groups of $n$ " in Figure 34 have to be understood in terms of how the students interpret the meaning of multiplication.

Hence, among elementary students, their generalizations can be assessed on the following points that are not necessarily mutually exclusive but related:

- (Type of relationship being Inferred) Are the generalizations iconic and indexical or symbolic?

- (Type and complexity of apprehension being manifested) What factors support and hinder the development of iconic and indexical generalizations?

- (Context of rule being inferred) What factors support and hinder the development of symbolic generalizations?

Figure 35 captures the sense in which pattern generalization competence emerges among elementary students. Following Deacon (1997), there is a bidirectional relationship among iconic, indexical, and symbolic generalizations with the symbolic ones drawing and operating on the relevant iconic and indexical forms that comprise them. Iconic representations are oftentimes the first to emerge. They are perceptually apprehended and are influenced by similarity of forms (numerical, figural, or both). Indexical representations emerge with operative apprehension via the spatial and numerical relationships that are inferred on the objects. Symbolic representations emerge as a logical consequence of seeing that a relationship between a particular sign and its object "is a function of the relationship it has" (Deacon, 1997, p. 86) with all the given and the projected stages in a pattern. 

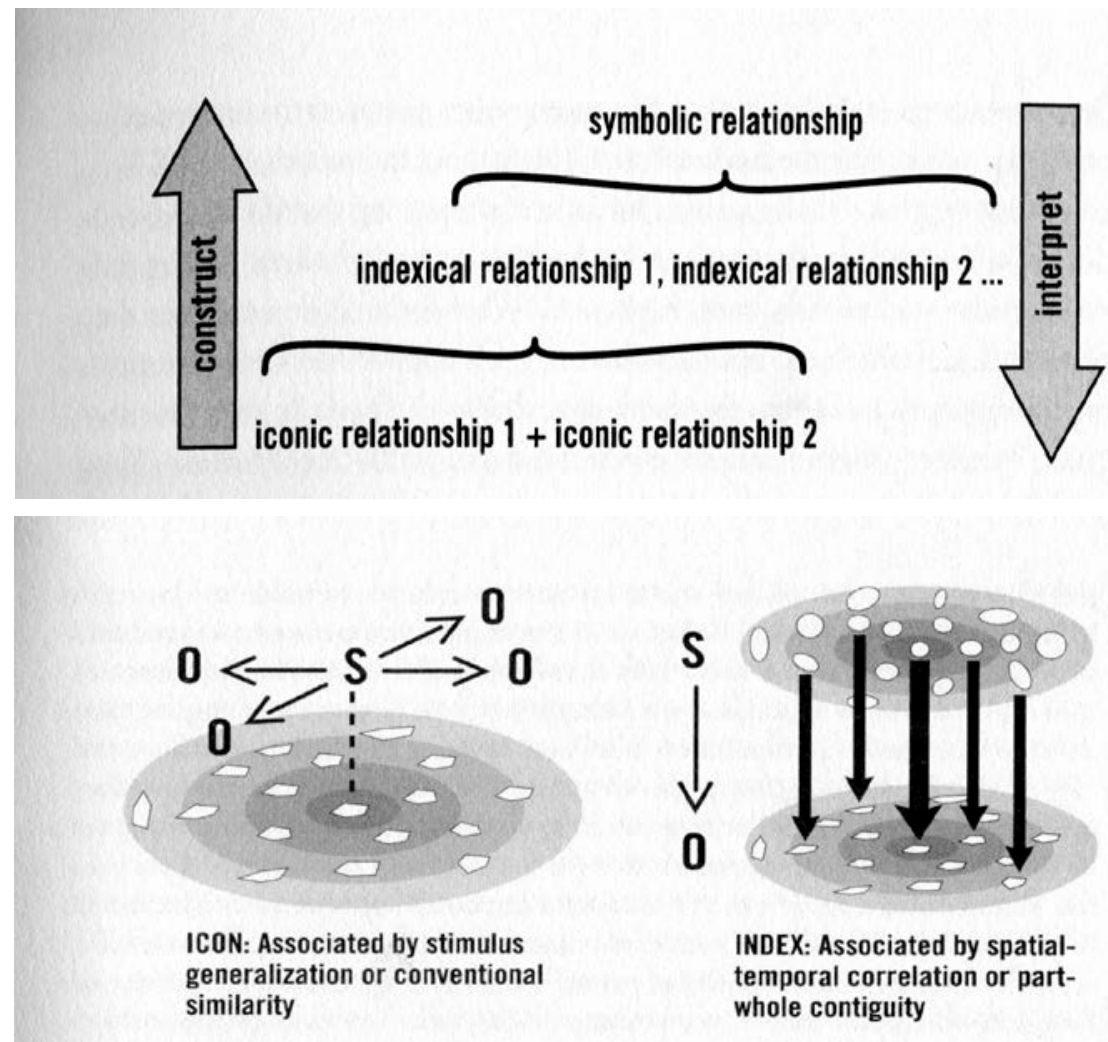

Figure 35. Emergent Models of Pattern Generalization Structures Among Elementary Students (Adapted from Deacon, 1997, pp. 75 and 79)

\section{IMPLICATIONS FOR MATHEMATICS TEACHING: HELPING ELEMENTARY STUDENTS SEE ARITHMETICAL NUMBERS AS INTUITED AND TACIT VARIABLES SUPPORTS GROWTH IN ALGEBRAIC THINKING}

Another significant finding that could be drawn from elementary students' ability to construct and justify incipient generalizations on certain patterns concerns the manner in which they treat arithmetical numbers in such contexts. That is, when appropriate patterning tasks are presented to them, they tend to manifest an implicit understanding and correct use of variables through arithmetical numbers. Certainly, having an inferred algebraically useful structure is a prerequisite. For example, the three students in Figure $\mathbf{3 4}$ were clearly cognizant of their abduced structures, hence, the use of arithmetical numbers emerged naturally during the process of induction. This situation resembles the static geometric-solving phase (Katz, 2007) in the history of algebra when AlKhwarizmi's famous rhetorical-driven (i.e. verbal-based) manual for solving arithmetical problems primarily employed concrete numbers as his way of demonstrating the manner in which "he grasp[ed] the procedure of [a] solution in its entire universality" (Kvasz, 2006, p 292). Concrete numbers to him and to those who were still oblivious to the use of variables used concrete numbers for illustrative purposes.

Referring once again to Radford's (2010) work with a small group of 3 Grade 2 Canadian students on the figural pattern shown on the left in Figure 31, they initially abduced an invariant structure for the pattern (i.e. two horizontal rows of squares determined by the stage number and the dark corner square) prior to performing induction involving stages 25,50, and 500. For Radford, their emergent in-action formulas implicitly employ an intuited variable. Further, such formulas evolve into a "more sophisticated form of algebraic thinking" (Radford, 2010, p. 80) when the intuited variable transitions into a tacit variable. In Radford's (2010) study, this transition occurred when the teacher pulled out several cards with labels corresponding to stage number (e.g. 5, 15, 100, 104, etc.) that prodded the students to obtain and verbally articulate a generalization on the basis of the stipulated stage number. Rivera's (2010) work with US second grade students also produced findings that were similar to Radford (2010). Prior to any formal intervention and within the context of a clinical interview, Rivera asked 20 Grade 2 US students to obtain generalizations for the three figural patterns shown in Figures 23, 24, and 25. As shown in Table 6, between 12 to 18 of the 20 students obtained correct far generalizations for the Figures 23 and 24 patterns and only 1 student provided a correct far generalization in the case of the Figure 25 pattern. 
Hence, having an algebraically useful structure - and not just any structure for that matter - supports the emergence of arithmetical numbers as concrete variables. Where Radford and Rivera differed in their finding deals with the modality in which their students expressed their tacit variable based generalizations. In Rivera's study, the students successfully generated tacit variable based generalizations in closed forms that they conveyed initially in a gestural-concrete mode and much later in pictorial form. The gestural-concrete mode enabled them to exhibit in-action formulas. In the pictorial mode, the students were initially shown a card with a label corresponding to the stage number. They then used a construction paper to draw the correct outcome for any far stage in the pattern that, following Radford (2010), is an indication of tacit variable based generalizing.

\section{IMPLICATIONS FOR MATHEMATICS LEARNING AND TEACHING: ENGAGING ELEMENTARY STUDENTS IN FIGURAL PATTERN GENERALIZATION PROCESSING FACILITIES GROWTH IN EARLY FUNCTION UNDERSTANDING}

In this final section, we focus on elementary students' understanding of functions in pattern generalization contexts. Recent research results drawn from classroom teaching experiments have shown younger children's natural capacity toward constructing and understanding functions in context. Based on their work with prekindergarten to Grade 1 students, Blanton and Kaput (2011) note that table-based functions help students organize covarying data, which then enable them to transform the collected information from opaque (i.e. merely as a storage for ordered pairs of numbers) to transparent (i.e. "looking through to see new relationships" (p. 11)). Cooper and Warren's (2011) study with Australian Year 5 students (ages 9 to 10 years) also indicate their ability to "understand the workings of function machines in terms of numbers" (p. 200). Moss and London McNab's (2011) work with 7- and 8-year-old students in Canada and the USA on function machines exemplifies natural connections that students make between such machines and their understanding of multiplication that enabled them to establish and construct rules for the numbers in the machines. The authors also point out the value of designing function tables that consist of cues appearing in a non-sequential order so that students' attention are focused on covarying (versus correspondence) relationships, which would then encourage them to generate explicit (versus recursive) rules. The studies of Carraher, Martinez, and Schliemann (2008) and Vale and Pimentel (2010) conducted with Grade 3 students (ages 8 to 9 years) in the USA and Portugal, respectively, also employed function tables that had sequential cues. However, the dependent column consisted of arithmetical expressions instead of mere outputs that reflected an emerging structure for the pattern.

For example, in Carraher, Martinez, and Schliemann's case, the pattern generalization task had the students obtaining the maximum number of people that could sit in $n$ number of detached square tables (one on each side). In the table provided to them, the dependent column contained the expressions $1 \times 4$ and $2 \times 4$ that encouraged the students to obtain an explicit rule for the pattern. In Vale and Pimentel's case, the pattern generalization task involves finding the total number of objects that comprised a growing regular hexagon with a pair of triangular tails growing on opposite sides of the hexagon and increasing by the stage number. The function table also had cues appearing in a sequential manner, however, the dependent terms reflected the students' emerging structure for the pattern, which took the form $1+n+n+$ or $1+2 \times n$, where $\mathrm{n}$ represents the stage number. In terms of curriculum development, Cai, $\mathrm{Ng}$, and Moyer (2011) note the value accorded to functions as a big idea in the Singapore mathematics curriculum, which is introduced in Grade 2 (mean age of 8 years). At that level, the students explore functional relationships in familiar numerical and figural contexts as an application of learning their multiplication facts and solving relevant multiplication problems.

Rivera's (2010) work with US Grade 2 students prior to formal instruction on patterns and functions also shows that some students have the ability to construct functional relationships. In Table 6, those students who were successful in constructing their far stages clearly saw and pictorially conveyed a relationship between stage number (as an input) and outcome in the absence of a function table. In other words, having an algebraically useful structure appears to be a minimal indicator that young children are capable of functional understanding. But, how deep is the content of their understanding of functions? Rivera assessed this issue in a clinical interview setting with the same second-grade cohort in a follow up study that took place the following year when the students were in third grade. He employed the same definition of a function that Carraher, Martinez, and Schliemann (2008) used in the context of their work with third grade students. For them, two ordered pairs $(a, b)$ and $(a, c)$ in a function imply $b$ $=\mathrm{c}$, that is,

[a] function is a relation that uniquely associates members of one set with members of another set. More formally, a function from $A$ to $B$ is an object $f$ such that every is uniquely associated with an object. A function is therefore a many-to-one (or sometimes one-to-one) relation. (Weistein quoted in Carraher, Martinez, and Schliemann, 2008, p. 10) 
The 11 students who were successful in constructing and justifying a direct rule for the Cross Pattern in Figure 33 (see Table 7) were all asked if it was possible to generate different outcomes for the same inferred rule. Interestingly enough, all 11 students initially drew or constructed figures that merely changed the orientation of the original figures by rotation (resulting in figures that reflect similitudes; see footnote 1). Hence, in this particular figural patterning context, while the numerical outcomes for both the original and rotated figures were the same, the students saw the figures as conveying two different outcomes (i.e., a constructed stage resulting from a dilation appeared to be different from a constructed stage resulting from a similitude).

Pattern generalization studies that have been conducted with middle school students (ages 11 and above) show that they tend to process patterns using a variety of numerical and additively recursive strategies. Among adults, for example, numerical generalizing strategies appear to be more frequently used over strategies that elementary school children have been documented to exhibit. For example, a majority of young children's correct incipient structural generalizations do not appear to be additively recursive but additively and multiplicatively functional. In other words, their use of visually drawn strategies naturally supports structural generalizations of the algebraic kind, unlike older individuals who, perhaps as a consequence of many years of training, tend to choose numerical strategies that could lead to correct variable-based generalizations. Unfortunately, many of those reported cases also demonstrate their inability to explain them because of weak to no abductions that could support their justifications.

\section{REFERENCES}

Alvarez, G., \& Cavanagh, P. (2004). The capacity of visual short-term memory is set both by visual information load and by number of objects. Psychological Science, 15(2), 106-111. https://doi.org/10.1111/j.09637214.2004.01502006.x

Bhatt, R., \& Quinn, P. (2011). How does learning impact development in infancy? The case of perceptual organization. Infancy, 16(1), 2-38. https:/ / doi.org/10.1111/j.1532-7078.2010.00048.x

Blanton, M., \& Kaput, J. (2004). Elementary grades students' capacity for functional thinking. In M. Hoines \& A. Fuglestad (eds.), Proceedings of the $28^{\text {th }}$ Conference of the International Group for the Psychology of Mathematics Education (Vol. 2, pp. 135-142). Bergen, Norway: PME.

Blanton, M., Brizuela, B., Gardiner, A., Sawrey, K., \& Newman-Owens, A. (2015). A learning trajectory in 6-yearolds' thinking about generalizing functional relationships. Journal for Research in Mathematics Education, 46(5), 511-558. https:// doi.org/10.5951/jresematheduc.46.5.0511

Cai, J., Ng, S.F., \& Moyer, J. (2011). Developing students' algebraic thinking in earlier grades: Lessons from China and Singapore. In J. Cai and E. Knuth (eds.), Early algebraization: A global dialogue from multiple perspectives (pp. 25-42). New York: Springer. https://doi.org/10.1007/978-3-642-17735-4_3

Carpenter, T., Franke, M., \& Levi, L. (2003). Thinking mathematically: Integrating arithmetic and algebra in elementary school. Portsmouth, NH: Heinemann.

Carraher, D., Martinez, M., \& Schliemann, A. (2008). Early algebra and mathematical generalization. ZDM, 40, 322. https:/ / doi.org/10.1007/s11858-007-0067-7

Carraher, D., Schliemann, A., \& Brizuela, B. (1999). Bringing out the algebraic character of arithmetic. Paper presented at the 1999 AERA Meeting, Montreal, Canada. Available at http:/ / www.earlyalgebra.terc.edu

Carraher, D., Schliemann, A., Brizuela, B., \& Earnest, D. (2006). Arithmetic and algebra in early mathematics education. Journal for Research in Mathematics Education, 37(2), 87-115.

Cavanagh, P., \& He, S. (2011). Attention mechanisms for counting in stabilized and in dynamic displays. In S. Dehaene \& E. Brannon (eds.), Space, time, and number in the brain: Searching for the foundations of mathematical thought (pp. 23-35). New York: Academic Press. https:/ / doi.org/10.1016/B978-0-12-385948-8.00003-7

Condry, K., \& Spelke, E. (2008). The development of language and abstract concepts: The case of natural number. Journal of Experimental Psychology: General, 137(1), 22-38. https://doi.org/10.1037/0096-3445.137.1.22

Cooper, T., \& Warren, E. (2011). Years 2 to 6 students' ability to generalize: Models, representations, and theory for teaching and learning. In J. Cai \& E. Knuth (Eds.), Early algebraization: A global dialogue from multiple perspectives (pp. 187-214). Netherlands: Springer Verlag. https:// doi.org/10.1007/978-3-642-17735-4_12

Deacon, T. (1997). The symbolic species: The co-evolution of language and the brain. New York: W. W. Norton \& Company.

Dehaene, S. (1997). The number sense. New York, NY: Oxford University Press.

Duval, R. (1998). Geometry from a cognitive point of view. In C. Mammana, \& V. Villani (Eds.), Perspectives in the teaching of geometry for the 21st century (pp. 29-83). Boston: Kluwer. 
Duval, R. (1999). Representation, vision, and visualization: Cognitive functions in mathematical thinking. In F. Hitt \& M. Santos (eds.), Proceedings of the 21st North American PME Conference (pp. 3-26). Cuernavaca, Morelos, Mexico: PMENA.

Feigenson, L. (2011). Objects, sets, and ensembles. In S. Dehaene \& E. Brannon (eds.), Space, time, and number in the brain: Searching for the foundations of mathematical thought (pp. 13-22). New York: Academic Press. https:/ / doi.org/10.1016/B978-0-12-385948-8.00002-5

Feigenson, L., \& Carey, S. (2003). Tracking individuals via object-files: Evidence from infants' manual search. Developmental Science, 6, 568-584. https:/ / doi.org/10.1111/1467-7687.00313

Gal, H., \& Linchevski, L. (2010). To see or not to see: Analyzing difficulties in geometry from the perspective of visual perception. Educational Studies in Mathematics, 74, 163-183. https:/ / doi.org/10.1007/s10649-010-9232$\mathrm{y}$

Goldstone, R., Son, J., \& Byrge, L. (2011). Early perceptual learning. Infancy, 16(1), 45-51. https:// doi.org/10.1111/j.1532-7078.2010.00054.x

Hill, C., \& Bennett, D. (2008). The perception of size and shape. Philosophical Issues, 18, $294-315$. https:/ / doi.org/10.1111/j.1533-6077.2008.00149.x

Kay, D. (2001). College geometry: A discovery approach. Boston, MA: Addison Wesley Longman, Inc.

Kvasz, L. (2006). The history of algebra and the development of the form of its language. Philosophia Mathematica, 14, 287-317. https://doi.org/10.1093/philmat/nkj017

Le Corre, M., \& Carey, S. (2007). One, two, three, four, nothing more: An investigation of the conceptual sources of the verbal counting principles. Cognition, 105, 395-438. https:/ / doi.org/10.1016/j.cognition.2006.10.005

Lee, L. (1996). An initiation into algebra culture through generalization activities. In C. Bednarz, C. Kieran, \& L. Lee (Eds.), Approaches to algebra: Perspectives for research and teaching (pp. 87-106). Dordrecht, Netherlands: Kluwer. https:/ / doi.org/10.1007/978-94-009-1732-3_6

Lipton, J., \& Spelke, E. (2005). Preschool children master the logic of number word meanings. Cognition, 1-10.

Luck, S., \& Vogel, E. (1997). The capacity of visual working memory for features and conjunctions. Nature, 390, 279281. https:/ / doi.org/10.1038/36846

Moss, J., \& London McNab, S. (2011). An approach to geometric and numeric patterning that fosters second grade students' reasoning and generalizing about functions and co-variation. In J. Cai \& E. Knuth (eds.), Early algebraization: A global dialogue from multiple perspectives (pp. 277-302). New York: Springer. https:/ / doi.org/10.1007/978-3-642-17735-4_16

Mulligan, J., Prescott, A., \& Mitchelmore, M. (2003). Taking a closer look at young students' visual imagery. Australian Primary Mathematics, 8(4), 175-197.

Pinel, P., Dehaene, S., Riviere, D., \& Le Bihan, D. (2001). Modulation of parietal activation by semantic distance in a number comparison task. Neuroimage, 14, 1013-1026. https:/ / doi.org/10.1006/nimg.2001.0913

Pizlo, Z., Sawada, T., Li, Y., Kropatsch, W., \& Steinman, R. (2010). New approach to the perception of 3D shape based on veridicality, complexity, symmetry, and volume. Vision Research, 50, 1-11. https:// doi.org/10.1016/j.visres.2009.09.024

Pothos, E., \& Ward, R. (2000). Symmetry, repetition, and figural goodness: An investigation of the weight of evidence theory. Cognition, 75, 65-78. https:// doi.org/10.1016/S0010-0277(00)00070-6

Radford, L. (2010). The eye as a theoretician: Seeing structures in generalizing activities. For the Learning of Mathematics, 30(2), 2-7.

Rivera, F. (2010). Second grade students' preinstructional competence in patterning activity. In M. Pinto \& T. Kawasaki (eds.), Proceedings of the $34^{\text {th }}$ Conference of the International Group for the Psychology of Mathematics Education (PME) (Vol. 4, pp. 81-88). Belo Horizante, Brazil: PME. https:/ / doi.org/10.1007/978-94-007-00147

Rivera, F. (2011). Toward a visually-oriented school mathematics curriculum: Research, theory, practice, and issues (Mathematics Education Library Series 49). New York, NY: Springer.

Schliemann, A., Carraher, D., \& Brizuela, B. (2007). Bringing out the algebraic character of arithmetic: From children's ideas to classroom practice. New York, NY: Erlbaum.

Schweitzer, K. (2006). Teacher as researcher: Research as a partnership. In S. Smith \& M. Smith (eds.), Teachers engaged in research: Inquiry into mathematics classrooms, grades pre-k-2 (pp. 69-94). Greenwich, CT: Information Age Publishing.

Schyns, P., Goldstone, R., \& Thibaut, J.-P. (1998). The development of features in object concepts. Behavioral and Brain Sciences, 21, 1-54. https:/ / doi.org/10.1017/S0140525X98000107 
Stavy, R., \& Babai, R. (2008). Complexity of shapes and quantitative reasoning in geometry. Mind, Brain, and Education, 2(4), 170-176. https:/ / doi.org/10.1111/j.1751-228X.2008.00051.x

Tanisli, D., \& Özdas, A. (2009). The strategies of using generalizing patterns among primary school $5^{\text {th }}$ grade students. Educational Sciences: Theory E Practice, 9(3), 1485-1497.

Taylor-Cox, J. (2003). Algebra in the early years? Young Children, 58(1), 15-21.

Triadafillidis, T. (1995). Circumventing visual limitations in teaching the geometry of shapes. Educational Studies in Mathematics, 15, 151-159. https:/ / doi.org/10.1007/BF01274092

Vale, I., \& Pimentel, T. (2010). From figural growing patterns to generalization: A path to algebraic thinking. In M. Pinto \& T. Kawasaki (eds.), Proceedings of the $34^{\text {th }}$ Conference of the International Group for the Psychology of Mathematics Education (PME) (Vol. 4, pp. 241-248). Belo Horizante, Brazil: PME.

Walkowiak, T. (2014). Elementary and middle school students' analyses of pictorial growth patterns. Journal of Mathematical Behavior, 56-71. https://doi.org/10.1016/j.jmathb.2013.09.004

Wallis, G., \& Bülthoff, H. (1999). Learning to recognize objects. Trends in Cognitive Sciences, 3(1), $22-31$. https:/ / doi.org/10.1016/S1364-6613(98)01261-3

Warren, E., \& Cooper, T. (2007). Repeating patterns and multiplicative thinking: Analysis of classroom interactions with 9-year-old students that support the transition from the known to the novel. Journal of Classroom Interaction, 41(2), 7-17.

Whitin, P., \& Whitin, D. (2011). Mathematical pattern hunters. Young Children, 84-90.

Wilkie, K. (2014). Learning to like algebra through looking. Australian Primary Classroom, 24-33.

Wilkie, K., \& Clarke, D. (2016). Developing students' functional thinking in algebra through different visualizations of a growing pattern's structure. Mathematics Education Research Journal, 28, 223-243. https:/ / doi.org/10.1007/s13394-015-0146-y

\section{http://www.ejmste.com}

